\title{
Calibration of Interest Rate Models - Transition Market Case
}

Martin Vojtek

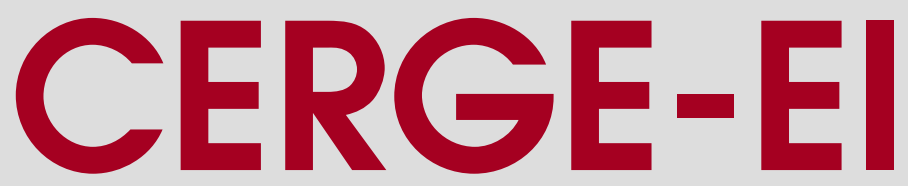

Charles University Center for Economic Research and Graduate Education Academy of Sciences of the Czech Republic Economics Institute 


\title{
Calibration of Interest Rate Models - Transition Market Case *
}

\author{
MARTIN VOJTEK ${ }^{\dagger}$ \\ CERGE-EI, Prague $\ddagger$
}

September 2004

\begin{abstract}
A methodology to calibrate multifactor interest rate model for transition countries is proposed. The usual methodology of calibration with implied volatility cannot be used as there are no markets for regularly traded derivatives. The existence of such a markets is essential for this calibration. The paradigm used is the Brace-Gatarek-Musiela model of interest rates (Brace, Gatarek and Musiela (1997)), which models the evolution of LIBOR (London InterBank Offered Rate) market interest rates, together with the Orthogonal GARCH model proposed by Alexander (2002), and further generalized by van der Weide (2002). The estimated model is used for the analysis of interest rate markets with shorter-end maturities in the 4 Visegrad countries (Slovak Republic, Czech Republic, Poland and Hungary).

V tomto článku je navrhnutá metodológia vhodná na kalibráciu viacfaktorových modelov úrokovej miery pre tranzitívne krajiny. Metodológia kalibrácie použitím implikovanej volatility, ktorá sa bečne používa, v tomto prípade je nevhodná, kedže v týchto krajinách nie je rozvinutý trh s derivátmi. Existencia takéhoto trhu je nevyhnutná pre takúto kalibráciu. Použitý model úrokových mier je model Brace-Gatarek-Musiela (Brace et al. (1997)), ktorý popisuje vývoj LIBOR úrokových mier, spolu s Ortogonálnym GARCH modelom, navrhnutým v Alexander (2002) a zovšseobecneným v van der Weide (2002). Táto metodológia je použitá na analýzu trhov s úrokovou mierou v krajinách Visegrádskej štvorky.
\end{abstract}

Keywords: interest rate, interest rate models, calibration, transition countries

JEL classification codes: C13, C32, C82, E43, G14

${ }^{*}$ I would like to thank Prof. Evžen Kočenda for regular consultations and supervising the research, as well as Prof. Jan Hanousek, Prof. Jan Kmenta, Prof. Ronald Anderson and Prof. Viatcheslav Vinogradov for their helpful comments and suggestions. This work was supported by the CERGE-EI/World Bank Fellowship. None of the above are responsible for errors in this paper.

${ }^{\dagger}$ CERGE-EI, P.O.BOX 882, Politických věznů 7, 11121 Prague 1, Czech Republic; telephone: +420 224005167; fax: +420 22421374; e-mail: martin.vojtek@cerge-ei.cz.

${ }^{\ddagger}$ A joint workplace of the Center for Economic Research and Graduate Education, Charles University, and the Economic Institute of the Academy of Science of the Czech Republic. 


\section{Introduction}

Theory about modelling the term structure of interest rates has evolved over the last 30 years, and since then a number of different approaches have been developed. This theory represents one of the most dynamic parts of the study of finance, where a lot of research is still going on with interesting practical applications, and therefore is widely used by both academics and practitioners ${ }^{1}$.

The term structure of interest rates concerns the relationship among the yields of default-free zero-coupon bonds that differ only with respect to maturity. Historically, three competing theories of the term structure have attracted attention. These are known as the expectations, the liquidity preference, and the hedgingpressure of preferred habitat theories of the term structure. According to the expectations theory, the shape of the yield curve can be explained by investors' expectations about future interest rates. The liquidity preference theory argues that short-term bonds are more desirable than long-term bonds because the former are more liquid. The last theory explains the shape of the term structure by the assumption that if an investor is risk-averse, he can be tempted out of his preferred habitats only with the promise of a higher yield on a bond of any other maturity.

Among the main uses of the interest rates models is their application to the pricing of derivatives of interest rates. To correctly determine the price of derivatives, one needs to have the model correctly calibrated to the market, which means estimating various parameters of the model in such a way that the model is able to reveal market development. A lot of work has been done in this field to calibrate interest rate models to the markets of developed countries ${ }^{2}$. However, such work for the markets of transition countries is very rare and has been done only in the private commercial sphere. The main problem is that the calibration methodology used for developed countries' markets cannot be used (reasons for this claim are described below).

One can assume that the number of various derivatives and the volume of trades in these derivatives will increase sharply in the coming years in the transition economies as the need for hedging of various risks is increasing with the development of these economies. Exact pricing methods are thus life-important, not only for business and traders, but also for the regulators of markets to avoid market failures.

In this paper the interest rates markets in transition countries are analyzed

\footnotetext{
${ }^{1}$ For a basic survey of research in this area, see Rebonato (1998). For more recent survey see techreport by Rebonato (2003)

${ }^{2}$ See the literature review section for some of the citations.
} 
from the point of view of the interest rate model of Brace et al. (1997). The main contribution of this paper is that it proposes to use GARCH modelling for the calibration of IR models and applies it to the emerging markets (where the standard techniques cannot be used). Also the issues connected with estimating the parameters of the mentioned interest rate model are analyzed. The analysis is done on daily data of 4 Visegrad countries (Poland, Slovakia, Hungary and Czech Republic), i.e., transition countries where the institutional reforms of economies are the most advanced.

In what follows I will depict the motivation for the research in this area, the aim of the research, main literature dealing with the area of research, proposed methodology and the estimation results and their analyses. Readers not familiar with the stochastic models of interest rates can find short descriptions and derivations in the appendix.

\section{Motivation for studying models of the term struc- ture}

Since the eighties and nineties the number and the volume of traded derivatives has increased sharply in the western fixed income markets. The number of products to satisfy the needs of users has developed. The general reason for the formation of new derivatives has been the need to hedge the interest rate risks of investors. Investors needed to insure against excessive increases or decreases in these rates and against twists in the shape of the yield structure. Therefore the main goals in modelling interest rates (IR) are to find a robust, credible model for the pricing of derivatives and a methodology of calibrating this model to the market data. When introducing a new class of derivatives, there is no benchmark price on the market. A model of interest rates can help retrieve this price from the market data only if it describes correctly the evolution of interest rates and if it is not misspecified with wrong values of parameters.

There is no single interest rate for the economy and in addition the structure of interest rates is interdependent. The interest rate is in general affected by a lot of factors and one of these, which impacts the interest rate for a particular security and which is fundamental in the modelling of interest rates, is the maturity, i.e., the date in the future when a bond is to be repaid. The relation between yield on zero-coupon bonds and maturity is referred to as the term structure of interest rates. In the following text I will refer to the models of interest rates sometimes also as models of term structure as these terminologies are equivalent. The analysis 
of term structure is crucial in the analysis of interest-rate-dependent derivatives and among its applications belong the following:

- The analysis of fixed income contracts with varying maturity; it has the biggest influence on the profitability of a portfolio in an environment with volatile interest rates.

- The forecasting of future interest rates.

- The pricing of derivatives and other contracts with fixed payments- in pricing financial bonds. It is important to look at yields of alternative investing opportunities with a similar length of commitment, and the term structure (or yield curve) gives information about these alternative yields.

- The pricing of options on assets with fixed income. This pricing requires the modelling of the development of the term structure of interest rates.

- The arbitrage possibility between various maturity bonds; the analysis of term structure can be useful in the comparisons of yields of these bonds.

- The expectations about the economy; it seems that the shape of the term structure curve has an influence on future economic activity, including investment and consumption and can incorporate useful information about future inflation.

There are a few of theories explaining the dynamics of the term structure of interest rates. In recent years, a new way of modelling the term structure has evolved entitled the stochastic process modelling of the term structure. This approach requires several assumptions: the term structure and bond prices are related to certain stochastic factors, these underlying factors are assumed to evolve over time according to a particular hypothesized stochastic process, and the interest rates and bond prices that result must satisfy no-arbitrage conditions. In addition, the valuation of options on fixed income securities all require some assumptions about the term structure generating process. Much of the research on the term structure field has been stimulated by the need to value such contingent claims.

The next step after setting up the model is to calibrate this model to the market data, which means to estimate the parameters of the model (usually the volatilities of interest rates and the correlations between various maturity interest rates). A lot of research has been done in the field of calibrating various models of IR to market data of developed countries (see next section); however; there is 
a gap in the field of calibrating models of IR to the transition countries' markets. There are a few reasons why this work has not been done yet: the models of IR usually contain strong assumptions about the efficiency of IR markets, there is a problem with access to the data (due to frequent changes in the recording of statistics), and so on.

The main reason for the failure of the calibration of more complex and complicated models of IR to transition markets is that these models are usually calibrated to exactly match the prices of some frequently traded derivatives, as for example swaptions or caps and floors ${ }^{3}$. But there is no market for these derivatives in transition countries, or at least these derivatives are traded very rarely and thus their prices are not reliable and the researchers cannot take them as benchmark prices. Therefore alternative techniques for the calibration of the models of IR or for the estimation of their parameters are needed.

As previously explained, the practitioners and the policymakers in transition countries have no access to the more complex pricing methods of IR derivatives. Everybody can agree that the number of various derivatives and the volume of trade in these derivatives will increase sharply in the coming years. This insight is based on the fact that hedging of an opened position is almost a necessity and with the development of markets various firms will demand such possibility. Exact pricing methods is thus life-important, not only for business and traders, but also for the regulators of markets to avoid market failures. This research would help to accomplish the goal of the precise calculation of derivatives prices. Also, the research should answer the question to what extent are these models reliable for pricing derivatives in transition markets. To achieve this, a method for calibrating multi-factors models of term structure for transition markets is proposed in this paper.

In the existing research there are two types of models of IR: models of shortrate and models of whole term structure. The former models are older and are based on the modelling of the interest rate over the smallest possible time interval, so-called the short rate. The whole term structure one can obtain from predicted future paths of the short-rate. The latter models are modelling the whole term structure at one time and thus are more complex and have more accurate pricing implications (Rebonato (1998)). They also allow various twists in the shape of the term structure, while the models of short-rate allow only increases or decreases of the whole term structure curve. The most freqeuntly used models of this class are Heath-Jarrow-Morton (Heath, Jarrow and Morton (1992)) and Brace-GatarekMusiela (Brace et al. (1997)) models. As already mentioned, the usual method

\footnotetext{
${ }^{3}$ In other words, the models are calibrated to implied volatility.
} 
of calibrating the BGM model is to calibrate it to the prices of caps. The BGM model offers a closed solution for the price of caps, where the parameters are volatilities of some forward rates. By inverting this formula, one can obtain the implied volatilities from the prices of the cap.

If, however, the researcher has no access to the prices of caps, the volatilities and correlations of various interest rates have to be estimated using other sources of data, but they have to be consistent with the market. So, the goal is to find a methodology to obtain consistent parameters from the market data available.

\section{Literature review}

The main streams of research in term structure modelling are the (general equilibrium) models of short rate, the stochastic volatility modelling and the no-arbitrage models of term structure.

The first to use a general equilibrium approach was Merton (1973) to derive a model of discount bond prices. His model was simply a Brownian motion with constant drift. The next to use a model of IR was Vasicek (1977), and his model belongs to the most used models of IR using this approach. Vasicek made the following assumptions: (A.1) The instantaneous (spot) interest rate follows a diffusion process; $(A .2)$ the price of a discount bond depends only on the spot rate over its term; and (A.3) the market is efficient. Under these assumptions, he showed by means of an arbitrage argument that the expected rate of return on any bond in excess of the spot rate is proportional to its standard deviation. This property is then used to derive a partial differential equation for bond prices. The solution to that equation is given in the form of a stochastic integral representation.

This general equilibrium model has a big disadvantage in that it allows for negative interest rates due to a constant coefficient for volatility. This setting was changed by Cox, Ingersoll and Ross (1985), who use an inter-temporal general equilibrium asset pricing model to study the term structure of interest rates. In this model, anticipations, risk aversion, investment alternatives, and preferences about the timing of consumption all play a role in determining bond prices. The volatility of the short rate depends on its value. Many of the factors traditionally mentioned as influencing the term structure are thus included in a way which is fully consistent with maximizing behavior and rational expectations. The model leads to specific formulas for bond prices which are well suited for empirical testing.

Calibration methodologies for these models are known and widely used. One of the approaches is the estimation of parameters of models using the Generalized 
Method of Moments, in this context pioneered by Chan, Karolyi, Longstaff and Sanders (1992). They found for U.S. treasury data that the models most successful in capturing the dynamics of the short rate are those that allow the volatility of IR changes to be highly sensitive to the level of these riskless rates. It is clear that these results have important implications for the use of the different term structure models in valuing interest rate' dependent derivatives. The problem is that the GMM method can give imprecise results. That was the motivation of Nowman (1997), who proposed a method of estimation based on the Gaussian estimation method of continuous time dynamic models (which means a method based on using the maximum likelihood technique). He found that for U.K. data, the findings of Chan et al. (1992) are not valid and that the volatility of the short rate is not sensitive to the level of rate in this case; for the U.S. data these findings are similar to Chan et al. (1992). Nowman (1997) uses another method of estimation, as his model allows the use of an exact maximum likelihood estimator, which can help reduce some of the temporal aggregation bias.

The next approach to modelling the IR is called no-arbitrage pricing. It evolved from the previous approach. One of the differences is that this approach describes the whole term structure, not only one of its point (as does the short rate in the previous text). It has two purposes in relation to the term structure of interest rates. The first is to price all zero coupon bonds of varying maturities from a finite number of economic fundamentals, called state variables. The second is to price all interest rate sensitive contingent claims, taking as given the prices of the zero coupon bonds. Heath et al. (1992) presented a unifying theory for valuing contingent claims under a stochastic term structure of interest rates. This methodology, based on the equivalent martingale measure technique, takes as given an initial forward rate curve and a family of potential stochastic processes for its subsequent movements. A no-arbitrage condition restricts this family of processes, yielding valuation formulae for interest rate sensitive contingent claims, which do not explicitly depend on the market prices of risk.

In most developed markets, caps and floors are the most traded derivatives. A cap is a strip of caplets each of which is a call option on a forward rate. Market practice is to price the option assuming that the underlying forward rate process is lognormally distributed with zero drift. Consequently, the option price is given by the Black-Scholes formula (Black and Scholes (1973)). In an arbitrage free framework, however, forward rates over consecutive time intervals are related to one another and cannot all be lognormal under one measure. Brace et al. (1997) show that the mentioned market practice can be made consistent with an arbitrage-free term structure model. 
Calibration of these models to the market data is much more problematic than in the case of short rate models. These models are driven by more independent factors and each forward rate has its own volatility parameters for these factors, which are interdependent. The correlation matrix of forward rates is also important in these models. All these parameters (volatilities and correlation matrix) have to be estimated from the market data consistently in order to preserve all relationships. The calibration methodology based on the prices of caps is described by Rebonato (1999). It can be extended to numerical simulations for determining the prices of path-dependent derivatives that are sensitive to interest rates.

However, no literature about the calibration of the models of IR to transition markets is available. The pricing approach of Rebonato (1999) cannot be used for transition countries as it is based on prices of caps and the volatility implied by these caps, and as mentioned in the previous section, these products are either not traded or their prices have often no explanatory power. The methodology of the calibration of short-rate models can be used without exceptions to calibrate the models for transition countries' data because they are based only on levels of interest rates.

The last approach to the modelling of the term structure is based on the so-called stochastic volatility assumption. It means that the volatility of the stochastic process itself follows a stochastic process. This method allows one to estimate a short rate process without loss of efficiency and consistency and uses the quasi-maximum likelihood method. The first to apply this approach is AitSahalia (1996). Ball and Torous (1999) estimate a stochastic volatility model of short-term riskless interest rate dynamics. Estimated interest rate dynamics are broadly similar across a number of countries and reliable evidence of stochastic volatility is found throughout. In contrast to stock returns, interest rate volatility exhibits faster mean-reverting behavior, and innovations in interest rate volatility are negligibly correlated with innovations in interest rates. The less persistent behavior of interest rate volatility reflects the fact that interest rate dynamics are impacted by transient economic shocks such as central bank announcements and other macroeconomic news.

\section{Models and methodology}

The first step is to get data about the interest rates from various transition countries and to calculate of the term structure over certain time periods. The parameters of the BGM model ${ }^{4}$ are possible to obtain either using the prices of traded

\footnotetext{
${ }^{4}$ They are volatilities and correlations of interest rates with various maturities.
} 
derivatives ${ }^{5}$ or using the information on conditional volatilities extracted using some model of conditional volatility (such as various types of GARCH models). In this work it is proposed to use the (G)O-GARCH model and describe how it can be used to achieve the calibration of parameters of the BGM model. GARCH models are based on the works of Engle (1982) and Bollerslev (1986) and are very popular in finance and more than suitable in capturing the changes in volatilities in models with high frequency data. The next subsections describe the basic theory of interest rate modelling and the calibration of the BGM model using the (G)O-GARCH model.

\subsection{Definitions and relationships}

The most basic contract based on the interest rate is an agreement to borrow a particular amount now in exchange for a promise to repay a bigger amount later. In general, the value of such agreement depends on the credibility of the debtor and factors other than the time value of money. However, in this paper it is not in our interest to find answers to these questions (credibility of debtor and so on), and thus it will be assumed that there is no possibility of default. Let us now define the basic concepts:

Let $T^{*}>0$ be a fixed time horizon for all activities in the market. Under discount bond with maturity $T \leq T^{*}$ let us mean the contract which pays out the owner of a unit of cash in the fixed time $T$ in the future. The price of the discount bond will be denoted as $P(t, T)$. Clearly, $P(T, T)=1$. For every maturity $T$ will be assumed that the price of bond $P(., T)$ follows a stochastic, strictly positive process.

The curve $P(t,$.$) describes the price of the whole spectrum of bonds with var-$ ious maturities. Let us define process $R(t, T)$, called yield to maturity. Formally,

$$
R(t, T)=-\frac{1}{T-t} \ln P(t, T) \quad \forall t \in\langle 0, T) .
$$

Under the term structure let us mean the functional relationship of yield $R(t, T)$ as a function of the maturity $T$. A forward contract is an agreement negotiated in time $t$ about paying out cash at some later time $T_{1}$ and receiving the payment back in time $T_{2}>T_{1}$. This claim can be replicated in time $t$ by buying $T_{2}$ bond and selling $k$ units of $T_{1}$ bonds. The initial costs are $P\left(t, T_{2}\right)-k P\left(t, T_{1}\right)$ in time $t$, debtor pays $k$ in time $T_{1}$ and he receives the $1 \$$ payment in $T_{2}$. To give

\footnotetext{
${ }^{5}$ That means to calibrate using implied or historical volatilities.
} 
this contract a zero value, $k$ has to be equal to

$$
k=\frac{P\left(t, T_{2}\right)}{P\left(t, T_{1}\right)} .
$$

Let us call the adequate payoff a forward rate covering the period $\left\langle T_{1}, T_{2}\right\rangle$ and will denote it as $f\left(t, T_{1}, T_{2}\right)$. So,

$$
\frac{P\left(t, T_{2}\right)}{P\left(t, T_{1}\right)}=e^{-f\left(t, T_{1}, T_{2}\right)\left(T_{2}-T_{1}\right)} \quad \forall t \leq T_{1} \leq T_{2},
$$

or

$$
f\left(t, T_{1}, T_{2}\right)=-\frac{\ln P\left(t, T_{2}\right)-\ln P\left(t, T_{1}\right)}{T_{2}-T_{1}} .
$$

If $T_{2} \rightarrow T_{1}$, we get an instantaneous forward rate

$$
f(t, T)=-\frac{\partial}{\partial T} \ln P(t, T)
$$

or equivalently

$$
P(t, T)=\exp \left(-\int_{t}^{T} f(t, u) d u\right) \quad \forall t \in\langle 0, T\rangle
$$

Let $r_{t}$ be an instantaneous interest rate over interval $\langle t, t+d t\rangle$. Then the process $B_{t}$ defined as

$$
B_{t}=\exp \left(\int_{0}^{t} r_{u} d u\right) \quad \forall t \in\left\langle 0, T^{*}\right\rangle
$$

will be called a savings account.

\subsection{The models of interest rates}

\section{The Heath, Jarrow, Morton (1992) model}

The earlier models of the term structure were based on the explicit modelling of short rate evolution. This approach has arisen from the need to price simple derivatives of the term structure, as for example options or swaps, which depend on one underlying bond. The approach by Heath et al. (1992), which models term structure evolution, is, on the other hand, based on the explicit specification of the dynamics of instant forward rates $f(t, T)$. This method is the generalization of older models, as shown in Baxter and Rennie (1996).

Let $W$ be $d$-dimensional Brownian motion defined on the filtered (in the sense 
of the Wiener filtration) probability space $(\Omega, \mathcal{F}, \mathbb{P})$. With the dot symbol $(\cdot)$ let us denote the standard product of vectors. The HJM model is based on the following assumptions.

(HJM.1) For the arbitrary fixed maturity $T \leq T^{*}$, the forward rate $f(t, T)$ is evolving in the following manner:

$$
f(t, T)=\int_{0}^{t} \alpha(s, T) d s+\int_{0}^{t} \sigma(s, T) \cdot d W_{s} \quad 0 \leq t \leq T,
$$

or in the differences

$$
d_{t} f(t, T)=\alpha(t, T) d t+\sigma(t, T) \cdot d W_{t}
$$

where the drift $\alpha$ and volatility $\sigma$ are stochastic processes with values in $\mathbb{R}$, resp. $\mathbb{R}^{d}$. Formally $\alpha: C \times \Omega \rightarrow \mathbb{R}, \sigma: C \times \Omega \rightarrow \mathbb{R}^{d}$, where $C=\left\{(u, t) ; 0 \leq u \leq t \leq T^{*}\right\}$.

(HJM.2) For the arbitrary maturity $T$, processes $\alpha(., T)$ and $\sigma(., T)$ are such that

$$
\int_{0}^{T}|\alpha(u, T)| d u+\int_{0}^{T}|\sigma(u, T)|^{2} d u<\infty \quad \mathbb{P} \text {-almost everywhere. }
$$

The HJM model characterizes the term structure by the following theorem (full treatment can be found in the appendix):

Theorem 1 For the arbitrary maturity $T \leq T^{*}$, under the assumption of nonexistence of arbitrage, the dynamics of the price of bond $P(t, T)$ under the riskneutral measure $\mathbb{P}^{*}$ is

$$
d P(t, T)=P(t, T)\left(r_{t} d t-b(t, T)\right) \cdot d W_{t}^{*}
$$

and the forward rate $f(t, T)$ satisfies

$$
d f(t, T)=\sigma(t, T) b(t, T) d t+\sigma(t, T) \cdot d W_{t}^{*},
$$

where $b(t, T)=-\int_{t}^{T} \sigma(t, u) d u$.

\section{The Brace, Gatarek, Musiela (1997) model}

The common feature of earlier models of interest rates (up to the HJM model) is the fact that (explicitly or implicitly) they include a specification of the stochastic behavior of non-observable financial quantities, as for example instantaneous forward rates. The calibration of these models to the set of market data thus 
needs some transformation of these data through the "black-box" of model to the dynamics of non-observable quantities.

This picture has radically changed with the introduction of the BGM (Brace et al. (1997)) model, which describes directly observable market quantities as discrete LIBOR forward rates.

Let us fix a positive real number $\delta$. Following the definition, the forward $\delta$ LIBOR rate $L(t, T)$ is a discrete forward rate over the interval $\langle T, T+\delta\rangle$ and is given by relationship

$$
1+\delta L(t, T)=\frac{P(t, T)}{P(t, T+\delta)} \quad \forall t \in\langle 0, T\rangle
$$

It is possible to find in the appendix the derivation of the dynamics of $L(t, T)$ under the risk-neutral measure. The advantage of the BGM is that the $L(t, T)$ rates can be modelled as lognormal.

\subsection{The calibration of the BGM model using the (G)O-GARCH model}

Let us discretize the BGM model in the following way (full derivation of this model can be found in the appendix):

$$
y_{i}^{t}=\frac{L\left(t+1, T_{i}\right)-L\left(t, T_{i}\right)}{L\left(t, T_{i}\right)}=\mu_{i}(t) \Delta t+\sum_{k=1}^{r} a_{i k}(t) \Delta W_{t}^{k},
$$

where $\Delta W_{t}^{k}$ is a increase at time $t$ of the $k$ th Brownian motion, $a_{i k}(t)$ are instantaneous volatilities of the $i$ th LIBOR rate belonging to the $k$ th factor (or Brownian motion), $\mu_{i}(t)$ is drift of the $i$ th LIBOR rate.

Let us suppose that we have $T$ observations $y_{i}^{t}$ on the returns of $k$ interest rate series with various maturities (i.e., one week, two weeks, one month, etc.). (G)O-GARCH models are based on the so-called principal component analysis, each component being a simple linear combination of the original returns series. The weights in these linear combinations are determined by the eigenvectors of the correlation matrix of the returns matrix. The principal components are ordered according to the size of eigenvalues (which are in fact variances of principal components) so that the first principal component, the one corresponding to the largest eigenvalue (i.e., the one with the largest variance), explains most of the variation. If the system is highly correlated (as it is assumed for interest rates with various maturities), only the first few eigenvalues will be significantly different from zero. This means that one can simplify the task by taking just few 
principal components into account to represent the original variables with a fairly high degree of accuracy.

The following text is based on Alexander (2002). Let us have the original returns in $T \times k$ matrix $\mathbf{Y}$. One can normalize these $k$ series into series with zero mean and unit variance, to get matrix $\mathbf{X}$. Now, let matrix $\mathbf{W}$ be the matrix of eigenvectors of $\mathbf{X}^{\prime} \mathbf{X} / T$, and $\boldsymbol{\Lambda}$ be the associated diagonal matrix of eigenvalues, ordered according to decreasing magnitude of eigenvalue. The principal components of $\mathbf{Y}$ are given by the matrix $\mathbf{P}$ :

$$
\mathbf{P}=\mathbf{X W}
$$

It can be shown that the matrix $\mathbf{P}$ is orthogonal. Because of orthogonality of matrix $\mathbf{W}$, (8) can be rewritten as $\mathbf{X}=\mathbf{P} \mathbf{W}^{\prime}$, which means

$$
x_{i}=w_{i 1} p_{1}+\cdots+w_{i k} p_{k}
$$

or

$$
y_{i}=\mu_{i}+\omega_{i 1} p_{1}+\cdots+\omega_{i r} p_{r}+\epsilon_{r},
$$

where $\omega_{i j}=w_{i j} \sigma_{i}, \mu_{i}, \sigma_{i}$ are the mean and standard deviation of $y_{i}$ and the error term $\epsilon_{i}$ means the approximation from using only $r$ out of the $k$ principal factors. When variances of (9) are taken into account, one gets

$$
\mathbf{V}=\mathbf{A D A}^{\prime}+\mathbf{V}_{\epsilon}
$$

where $\mathbf{D}=\operatorname{diag}\left(V\left(p_{1}\right), \ldots, V\left(p_{r}\right)\right)$ is a diagonal (because of orthogonality) covariance matrix of chosen $r$ principal factors, $\mathbf{A}=\left(\omega_{i j}\right)$ and $\mathbf{V}_{\epsilon}$ is the covariance matrix of the errors. Ignoring the error term gives us the approximation that forms the basis for the model of covariance matrix $\mathbf{V}$

$$
\mathbf{V} \approx \mathbf{A D A}^{\prime}
$$

Because matrix $\mathbf{A}$ is known, it is enough to model matrix $\mathbf{D}$, which can be achieved by running $r$ simple GARCH models on the first $r$ principal components from $\mathbf{P}$. This is the basis of the O-GARCH model.

The main limitation of this approach is that the principal components are only unconditionally uncorrelated so the assumption that off-diagonal elements of $\mathbf{D}$ are zero may be unnecessarily strong. This assumption has been relaxed by van der Weide (2002), who develops a generalization of the model called Generalized O-GARCH. In this model the univariate GARCH specifications are applied 
to transformed variables $\mathbf{P}^{*}=\mathbf{P U}$, where $\mathbf{U}$ is an orthonormal matrix which can be estimated using conditional information from the observed data.

Now, let us closely look at the specification (7) and (9). Because the series $p_{1}, \ldots, p_{r}$ are generated from the series with zero mean and unit variance, one can consider them as increases of $r$ Brownian motions, so that estimates of coefficients $\omega_{i j}$ are actually estimates of the conditional volatility belonging to the $j$ th Brownian motion. After obtaining these estimates (using (G)O-GARCH), the next step is needed.

As these estimates are just averages of instantaneous volatilities, the researcher needs to choose the appropriate functional form for the time profile of these volatilities. As a suitable form, Rebonato (2002) recommends writing instantaneous volatility $a_{i k}\left(t, T_{i}\right)$ (redundant parameter $T_{i}$ is added to better determine the rate maturing at time $T_{i}$ ) as a product of a maturity specific term and of a time-tomaturity specific term:

$$
a_{i k}\left(t, T_{i}\right)=g\left(T_{i}\right) h\left(T_{i}-t\right)
$$

Rebonato (2002) also recommends suitable possible functional form for both $g, h$ functions.

The last step in the calibration process is to perform numerical simulation of future term structure evolution. One possible simulation algorithm is described by Brace, Musiela and Schloegl (1998). These numerical simulations then can be used for the construction of processes of derivatives as well as replicating portfolios needed for their comparisons.

\section{Data description}

In this research, data from the 4 Visegrad countries are used: Slovak Republic, Czech Republic, Hungary and Poland. Various time spans have to be used as the quotations vary across the countries. The data-sets for the Slovak Republic and the Czech Republic come from the web pages of central banks, the data-sets for Hungary and Poland come from Reuters' databases. All interest rate series used are the analogue of LIBOR (London InterBank Offeres Rates). In this work only data for the shorter end of the term structure are used (the tenor with maturities from 1 week to 1 year). There are a few reasons for such a restriction.

The markets in transition countries are often imperfect and non-developed and the interest-rate market is not an exception. Although countries mentioned in the previous paragraph have the most developed markets among the transition countries, they are still not at the level of developed countries. The interest-rate 
market is a very good example as banking institutions lend and borrow mostly money with the shortest maturities and official quotations of interest rates exists only for maturities up to 1 year. The pricing of instruments with longer maturities is based on swaps and rates calculated from swaps. These rates are quoted by Reuters (except for the Slovak Republic), but as was mentioned above, with longer maturities the market is even more imperfect. Mostly there exist only government bonds with higher maturities; municipal or corporate bonds exist only rarely.

So the reasons for restricting the data-sets to maturities up to one year are market imperfections and liquidity (no trading with longer maturities - the volume of trades is often zero for longer maturities) and data availability. These estimations concentrate on the interbank offered rates, not on the rates which are implied in the prices of government bonds. There are few reasons for that. Firstly, the BGM model describes the evolution of interbank offered rates. Secondly, these rates, although in general not risk-free (there is always a risk of bankruptcy of a bank, which is incorporated in the rates), are used by banks and other financial institutions as the lending and borrowing rates, and therefore they are used for the pricing of derivatives.

The following data are used:

- Czech Republic - Prague InterBank Offered Rate (PRIBOR) - the analogue of LIBOR rates, time span is from 2 January $1998^{6}$ to 28 November 2003, which comprises 1492 daily observations. In this case the 8 PRIBOR interest rate time series with maturities from 1 week to 1 year are used. The time evolution can be found in Figure 1. The basic characteristics of the data are in Table 1. In Table 2 one can see the eigenvectors of the unconditional variance matrix, i.e., the weights of respective interest rates in principal factors. There are also the eigenvalues of the unconditional variance matrix (equal to the unconditional variances of principal factors) and the fraction of total variance explained by the concrete principal factor.

- Slovak Republic - Bratislava InterBank Offered Rate (BRIBOR) - the analogue of LIBOR rates, time span is from 5 June 2000 to 28 November 2003 (earlier data are not usable as the rates were quoted only up to 6 months maturity), which consists of 871 daily observations. The data used were 8 BRIBOR interest rates time series with maturities from 1 week to 1 year. The time evolution can be found in Figure 4. The basic characteristics of

\footnotetext{
${ }^{6}$ Although it would be possible to use a longer time span, it would not be very useful. The interbank market was underdeveloped and unstable before 1998 as there were few institutions which needed large amounts of credit and they were able to unbalance the whole market. For more information see Hájková, Hanousek and Němeček (2002).
} 
the data are in Table 4 . Table 5 shows the eigenvectors of the unconditional covariance matrix together with eigenvalues.

- Hungary - Budapest InterBank Offered Rate (BUBOR) - the analogue of LIBOR rates, time span is from 2 May 2002 to 28 November 2003, which includes 406 daily observations. In the case of Hungary 7 interest rate time series with maturities from 1 week to 1 year are used(the series with 2 months' maturity was not at disposal). The time span is much shorter than in the previous cases. It is due to the fact that until May 2002 only rates for one, three and six months maturity were quoted in the market. The evolution of these rates and their basic characteristics are in Figure 7 and Table 7. Table 8 shows the eigenvectors and eigenvalues.

- Poland - Warsawa InterBank Offered Rate (WIBOR) - the analogue of LIBOR rates, time span is from 2 January 2001 to 28 November 2003 (again, no quoting of longer rates occurred beforehand), which comprises 739 daily observations. 6 interest rate time series with maturities from 1 week to 1 year were used (again, the series for 2 weeks' and 2 months' maturities were not quoted). The evolution of these rates and their basic characteristics are in Figure 10 and Table 10. Table 11 shows the eigenvectors and eigenvalues.

\section{Estimation Techniques}

For all currencies the original interest rate time series were transformed in order to fit the BGM model specification. The time series used in estimations are constructed as yields of these original interest rate processes. For all currencies 3 principal factors were chosen, as they explain more than $95 \%$ of variance in all cases (except Poland, where it is $93 \%$ ). Although the $3^{\text {rd }}$ factor was sometimes relatively unimportant (e.g., Hungary, where it explained only 2.1 per cent of variance), it was chosen for modelling to have uniform results and due to the possibility of change in the shape of the term structure ${ }^{7}$.

The time series of principal factors were calculated using the procedure described in the Methodology section. When there was the suspicion of autocorrelation in the principal factors ${ }^{8}$, the correction for it was used in the mean equation

\footnotetext{
${ }^{7}$ From the tables of principal component weights one can see, as is usual in the principal component analysis, that the first component directs the horizontal movements of the term structure, the second one directs the changes in slope and the third directs the changes in curvature of the term structure.

${ }^{8}$ For example, when the Ljung-Box statistics were sufficiently high for some of interest rates time series.
} 
(using lags of dependent variable) for the O-GARCH model. All model specifications were tested using a battery of specification tests. The specification tests used in the selection of the number of lags in the mean equations and the number of parameters in the O-GARCH specifications were the Ljung-Box test, Likelihoood ratio (LR) test and the Lagrange Multiplier (LM) test on squared standardized residuals proposed by Engle (1982). Standardized residuals were also tested by the Sign Bias test, the Negative Bias test and the Positive Bias test, proposed in Engle and Ng (1993). These test are designed to examine whether the volatility models are not misspecified in the sense that they are able to deal with the potential asymmetry in the reaction to positive and negative shocks (Sign Bias test) or the potential asymmetry in the reaction to the magnitude of shock (Negative Bias test and Positive Bias test).

As the autocorrelation is present for the rates with higher maturities in the Czech Republic, the correction for autocorrelation in the modelling of principal factors is reasonable. The mean equation for the principal components is specified with constant and one (for the first and third component) or two (for the second component) lags. The conditional variances were specified as the $\operatorname{GARCH}(1,2)$ processes for the second and third component and as the $\operatorname{GARCH}(1,1)$ process for the first component, so that

$$
p_{t}=c+b_{1} p_{t-1}\left(+b_{2} p_{t-2}\right)+\mu_{t}, \mu_{t} \sim N\left(0, H_{t}\right),
$$

where the diagonal elements of $H_{t}$ are described by

$$
h_{i, t}=\alpha_{0}+\alpha_{1} \mu_{i, t-1}^{2}+\beta_{1} h_{i, t-1}\left(+\beta_{2} h_{i, t-2}\right), i=1,2,3,
$$

and the off-diagonal elements of $H_{t}$ are $0^{9}$. The results of O-GARCH procedures on these principal factors are in Table 3 , as well as the values of the log-likelihood function and the Schwarz Bayes Information Criterion. There are also the values of Ljung-Box statistics for standardized residuals $\left(Q_{10}\right)$ and squared standardized residuals $\left(Q_{10}^{2}\right)$ for 10 lags. They have $\chi^{2}$ distribution with 10 degrees of freedom. The last row is the value of statistics for the LM test with 5 lags, the distribution of these statistics is $\chi^{2}$ with 5 degrees of freedom ${ }^{10}$. All specifications of the model that were used in estimation minimized the Schwarz criterion among all tested specifications. Also, LR tests rejected the null hypothesis that some coefficient has zero value. The Ljung-Box test based on the $Q_{10}$ statistics does not reject

\footnotetext{
${ }^{9}$ The terms in brackets were added for the second factor.

${ }^{10}$ The critical values at $95 \%$ significance level are 18.31 and 11.07 for 10 and 5 degrees of freedom for this distribution.
} 
the null hypothesis, thus there is no autocorrelation present in the standardized residuals, i.e., more lags are not necessary in the mean equation. The Ljung-Box test on squared standardized residuals is the test for the presence of second order dependence in the residuals. From Table 3 one can conclude that the models are well specified, so that there is no additional heteroscedasticity in the residuals. This conclusion is further supported by the LM test of the null hypothesis that no $\mathrm{ARCH}$ process is presented in the residuals. This hypothesis cannot be rejected on any reasonable level of significance. All 3 specifications were tested using above mentioned bias tests with the result that one cannot reject the hypothesis that the volatility processes are not misspecified.

When taking the case of the Slovak Republic, it is possible to see that there is a strong autocorrelation presented in the data (from the $Q$ statistics in Table 4). The above mentioned specification tests were performed and 3 lags in the mean equation and $\operatorname{GARCH}(1,1)$ for variance process were chosen as the optimal specification for the second and the third factor. The first factor is much more problematic. From the time evolution of interest rates in the Slovak case one can see a sharp drop around the end of November in 2002, caused by a decrease in the central bank's discount rate. This drop is represented by extremely large values in the first factor, which caused either some numerical instability in the GARCH parameters estimation or even the impossibility of numerical estimation. Due to numerical instability it is not possible to change this outlier as it would change dramatically the estimated values of parameters. Under these conditions, the one with 2 lags in the mean equation and $\operatorname{GARCH}(2,1)$ parametrization was chosen as the best specification for the first factor. The results of the estimation are in Table 6. The Negative and Positive Bias tests show that the processes are not misspecified. The Sign Bias test returns significant statistics for the third factor, where the residuals are slightly asymmetric. The second order effects in the residuals are however captured, and all other tests are positive for this specification.

For Hungary, there is no autocorrelation presented as the $Q$ statistics are statistically not significant. Thus in this case it is possible to use the mean equation without lags of dependent variables. After the usual specification testing procedure, one can conclude that the most appropriate model is $\operatorname{GARCH}(1,1)$ in all cases. However, the LR tests and the Schwarz criterion indicated other feasible specifications, but in order to have a more parsimonious model I decided for the simple GARCH $(1,1)$ process without lags in the mean equation. The other possibility was the specifications with 2 or 3 lags in the mean equation and $\operatorname{GARCH}(2,0)$ or $\operatorname{GARCH}(1,2)$ processes. The former mentioned specification can be used because not only the Sign Bias tests indicated that it is the correct specification but 
also the Ljung-Box and the LM tests have fairly low (insignificant) statistics. The estimation results are in Table 9.

The rates for Poland show the significant presence of autocorrelation as the $Q$ statistics are statistically significant for all rates except the one with three month maturity. However, after the specification testing procedure, one can decide to employ one lag of the dependent variable on the RHS of the mean equation only for the first and the third factor. For the second factor it was not necessary, as was shown by the LR test and the Ljung-Box on the residuals. So, the changes in a shape of the yield curve in this case does not depend on past observations. The standard deviation of the changes in interest rates are higher than in the previous cases. Also the weights of principal components are higher. These facts signalize that the volatilities for interest rates in Poland are of higher levels than those for the previous currencies: one could observe this mainly at the shortest examined rate. The Sign Bias tests again do not show any misspecification of the model, as the histogram of residuals is symmetric around 0 .

\section{$7 \quad$ Estimation results}

\subsection{Czech Republic}

As expected, the constant coefficients in the mean equations are statistically unimportant. However, the sums of $\beta$ coefficients for the second and the third factor are large, showing that there are fairly persistent volatilities of components and that these components in the Czech case are almost nonreactive to the inflow of new information. The opposite case is the first factor. The constant term in the GARCH specification is large together with the high value of $\alpha_{1}$ coefficient. It follows that the volatility of the first factor is high and is very dependent on past income of news. The higher shock is followed by the period of higher volatility. This suggests that after the horizontal movement of the whole yield curve (which is the consequence of a shock in the first factor) one can expect more intensive trading in the next trading day. This result is consistent with the observed facts that the interest rates in the Czech Republic show a very low level of volatility and they remain relatively fixed for a number of days and the periods of relatively higher volatilities follow mainly after the drops in the yield curve levels. This is also supported by the levels of weights for the first principal component, whose values vary at around 0.35 , so only one third of the shock is translated into the movement in the horizontal direction. The high minimal value of the variance of shock in the first factor (i.e., $\alpha_{0}$ ) indicate that it is much more probable to have 
an unexpected shock in the horizontal movement of the yield curve than in the change of its slope or shape.

Using the estimated results, it is possible to generate the time evolution of instantaneous conditional covariance and correlation matrices. As an illustration, the conditional correlation matrix of PRIBOR rates as seen on the market on 28 November 2003 can be found in Figure 2. Figure 3 shows the estimated instantaneous conditional volatility of the 1 month PRIBOR rate.

Both images are fairly consistent with the data. Although the overall volatility level is low, the periods of "increased" volatility level in Figure 3 correspond to the periods with higher market activity (mostly after significant drops in the interest rate, which also confirms the conclusions from the previous paragraphs). Similarly, the correlation surface calculated is consistent with the market development seen around the end of November 2003.

From these facts is it clear that the calibration procedure is able to reveal the true market development and as such can be used in the pricing of IR sensitive derivatives. We are able to ascertain the development of conditional correlations and volatilities among the rates, which are factors influencing the prices of such derivatives.

\subsection{Slovak Republic}

The analysis of results is different from the previous case. The constant coefficients are again statistically unimportant, as one may expect. What is more interesting is the fact that the lag coefficient are (except the $2^{\text {nd }}$ lag for the first factor) negative. This means that greater changes (in absolute values) of the factors tend to be followed by smaller changes of the opposite sign. So, for example, a higher increase in the level of interest rates should be followed by a smaller decrease of the level (or vice-versa), which is a correction often observable in financial markets. For the first factor there is some autocorrelation left in the residuals, as one can observe from the value of $Q(10)$ statistics, however, using more lags does not help. We are interested mainly in the volatility analysis. The LM test statistics are fairly low in this case, similarly as are $Q^{2}(10)$ statistics, which is a sign that heteroscedasticity or second order effects were well captured in this case. From the estimation results one can observ that the processes for variances of the shocks $\left(h_{i, t}\right)$ look like there are strong suspicions for unit root presence, as the sum of $\alpha$ and $\beta$ coefficients is very close to zero. The reaction to the inflow of new information concerning the variance of the first component is very high, so there is a high probability that a shock in the first component will influence the 
volatilities of interest rates significantly. The persistence of the variance is fairly high for the last two components and thus the variance stays high for a longer time after a high shock. All these results suggest that the volatility of the interest rates in Slovakia could be fairly high after high shocks.

The next figure is the correlation surface as of 28 November 2003 (Figure 5). The time evolution of volatility of the 1 month BRIBOR rate is in Figure 6 . The volatilities higher than 0.06 are not in this graph in order to increase the resolution of the figure. Here it is possible to see the confirmation of the conclusions from the previous paragraph that the high shock in the first factor will influence very significantly the volatility of rates. The highest shock is dated 18 November 2002, when the Slovak Central Bank lowered the discount rate (at that time the official rate for the refinancing of banks) from $8 \%$ to $6.5 \%$. Thus in the next few days the conditional volatility was affected for all rates, as can be seen from Figure 4. Otherwise, the conditional volatility is low, mostly under $1 \%$. Due to this sharp change in level, it would be more suitable to use some type of switching regime GARCH. However, there are only 250 observations after the break, which are not enough to ensure stability of estimated coefficients. This use of switching regime would also be more reasonable from the pricing point of view. The estimated volatility levels are unnecessarily high and it took some time for the shock to disappear.

With the exception of this break in level of the interest rates, our approach is able to reveal the market course of events. For example, the correlation surface shows can reveal the fact that in the last examined trading days the longer maturities (from 6 to 12 months) were stable, while the shorter ones were increasing. This is in accordance with Figure 5, where there is a small negative correlation between short-term and long-term IR rates. Also to model is able to capture second order effects of all factors, as the residuals show no evidence for heteroscedasticity. However, the estimation problems and numerical instability are drawbacks in the case of the Slovak Republic. This is mainly caused by the great change in the level of interest rates.

\section{$7.3 \quad$ Hungary}

The results of the estimation are quite interesting. Both $Q$ statistics are equal almost to zero, similarly to the LM test statistics. This is a sign that there is no autocorrelation hidden in the residuals as well as no second order effects. Coefficients by innovation term $\left(\alpha_{1}\right)$ are very high for all 3 estimated principal components. This means that the impact of shocks to instantaneous variance in 
the next period is large. This fact can indicate that after significant shocks, the intensity of trading increases. On the other side, the persistence of the variance is even lower than in the case of the Slovak crown. The $\alpha_{0}$ coefficient for the first factor, meaning the constant in the volatility process, is relatively high so that the variance or volatility connected with the first coefficient should be higher than with the previous currency. With the next figures, it is possible track the consequences of these facts. The shocks are much more frequent than in the previous cases, and they also do not have a long duration. Moreover the rates have higher volatilities after the shocks (probably due to more intensive tradings). Also the estimated correlations at the end of November 2003 are in line with the evolution of the market (Figures 8,9), where the rates are decreasing simultaneously. The correlation between the shortest and the longest rate is around 0.6. Figure 9 is again adapted in such a way that the volatilities higher than 0.2 are not shown in this graph in order to increase the resolution of the figure.

The previously stated facts may cause problems when using this calibration for pricing IR derivatives, as the external shocks to volatility are too high and too frequent. When comparing the estimated periods of high volatility with Figure 7, it is possible to conclude that the model is again able to capture the periods of high volatility in the data, however, these periods may cause instability of prices dependent on these factors.

\subsection{Poland}

From the results of the regression in Table 12, it is clear that in this case, there is no suspicion for the presence of an unit root in the GARCH processes. The first and the third components have a fairly persistent variance, however, the second component shows a higher responsiveness to the random shocks. This means that the trend in the changes in the level is stable (with small influences from innovations), while the changes in the slope are more chaotic but last only for a short time. This is also in accordance with the conclusion from the last paragraph that the second factor does not account for autocorrelation and thus does not depend on past movements. Total variance explained by the first factor is relatively low in the case of Poland; it suggests that the volatility of rates are more connected with higher factors. The high weights of the second factor for the shorter maturities correspond with the observed volatile movements of these maturities.

In Figure 12 one can see that in November 2003, the one month interest rate had a higher volatility than the long-term average. This may be the reason for 
lower correlations of shorter interest rates (week and month) with the longer interest rates, as is it observable in Figure 11. Also, the predicted behavior of the volatility can be seen. The high persistence of the variance (showed by the large values of $\beta_{1}$ parameters) is visible, as periods with higher volatility alternate with periods with lower volatility. This fact can be seen as a confirmation that in this case the calibration methodology is suitable and the conditional parameters coincide well with the market development. From all 4 countries the Polish market seems to be the most suitable for the development of interest rate derivatives. There are no sudden breaks in the levels, the estimation procedures work very well in this case and the specifications of factor are very parsimonious. 


\section{Conclusions}

In this paper a new methodology is proposed for the calibration of the BraceGatarek-Musiela (BGM) model of interest rates. The BGM model is chosen because it is one of the most sophisticated models of interest rates and it has very good pricing implications. A new way to perform the calibration is needed in cases where the standard calibration technique (calibrate to fit prices of caps or swaptions, i.e., implied volatility) could not be used. The methodology is used for the calibration of this model to the markets of 4 transition countries (Czech Republic, Slovak Republic, Hungary and Poland) and an analysis of these markets is carried out based on the calibration.

There are more reasons why to perform such research. The exact pricing of derivatives is very important not only for business but also for policymakers. An example of the importance of exact pricing for business is hedging. Hedging based on derivatives can be successful only if correct prices of derivatives are available; otherwise, there is a possibility of arbitrage. For the market regulator it is essential that the correct pricing rules can be set up to avoid market failures. Another notable outcome of the research is that it may help to start up trades with derivatives in the emerging markets.

The estimation results and estimated evolution of conditional volatilities and correlations (which are in fact the parameters of the BGM model) are generally in correspondence with the true market development. However, only the Czech and Polish markets are developed to such degree that it is possible to use the calibrated interest rate model for pricing IR sensitive derivatives. The other two countries (Slovakia and Hungary) do not have markets developed enough to use such a strong model for pricing IR derivatives. 


\section{References}

Ait-Sahalia, Y., "Testing Continuous-Time Models of the Spot Interest Rate," Review of Financial Studies, 1996, 9, 385-426.

Alexander, Carol, "Principal component models for Generating Large Covariance Matrices," Economic Notes: Review of Banking, Finance and Monetary Economics, 2002, 31, 337-359.

Ball, C. A. and W. N. Torous, "The Stochastic Volatility of Short-Term Interest Rates: Some International Evidence," The Journal of Finance, 1999, 54, 2339-2359.

Baxter, M. W. and A. J. O. Rennie, Financial Calculus - An Introduction to Derivative Pricing, Cambridge, UK: Cambridge University Press, 1996.

Black, Fischer and Myron Scholes, "The Pricing of Options and Corporate Liabilities," Journal of Finance, 1973, 81, 637-654.

Bollerslev, Tim, "Generalized Autoregressive Conditional Heteroscedasticity," Journal of Econometrics, 1986, 31, 307-327.

Brace, Alan, Darius Gatarek, and Marek Musiela, "The Market Model of Interest Rate Dynamics," Math. Finance, 1997, 7, 127-154.

, Marek Musiela, and Erik Schloegl, "A Simulation Algorithm Based on Measure Relationships in the Lognormal Market Model," Statistics Preprint Series S98-21, The University of New South Wales, Sydney, Australia 1998.

Chan, K. C., G. A. Karolyi, F. A. Longstaff, and A. B. Sanders, "An Empirical Comparison of Alternative Models of the Short-Term Interest Rate," The Journal of Finance, 1992, 47, 1209-1227.

Cox, J., J. Ingersoll, and S. Ross, "A Theory of the Term Structure of Interest Rates," Econometrica, 1985, 53, 385-407.

Engle, Robert F., "Autoregressive Conditional Heteroscedasticity with Estimates of the Variance of United Kingdom Inflation," Econometrica, 1982, $50 / 4,987-1006$.

and Victor K. Ng, "Measuring and Testing the Impact of News," Journal of Finance, 1993, 48/5, 1749-1778. 
Hájková, Dana, Jan Hanousek, and Libor Němeček, "The Czech Republic's banking sector: Emerging from turbulent times," in "Cahiers Papers: The financial integration of an enlarged EU: Banking and capital markets," Vol. 7, European Investment Bank, 2002, pp. 55-75.

Heath, D.C., R.A. Jarrow, and A. Morton, "Bond Pricing and the Term Structure of Interest Rates: A New Methodology for Contingent Claims Valuation," Econometrica, 1992, 60, 77-105.

Merton, Robert C., "Theory of Rational Option Pricing," Bell Journal of Economics, 1973, 4, 141-183.

Musiela, Marek and Marek Rutkowski, Martingale Methods in Financial Modeling, 2nd ed., Springer-Verlag, 1998.

Nowman, K. B., "Gaussian Estimation of Single-Factor Continuous Time Models of the Term Structure of Interest Rates," The Journal of Finance, 1997, 52, 1695-1706.

Rebonato, Riccardo, Interest-Rate Options Model, 2nd ed., John Willey \& Sons, Inc., 1998.

_ _ , "On the simultaneous calibration of multifactor lognormal interest rate models to Black volatilities and to the correlation matrix," The Journal of Computational Finance, 1999, 2, 6-27.

_ Modern Pricing of Interest-Rate Derivatives, Princeton University Press, 2002 .

__ , "Term-Structure Models: a Review," Technical Report, QUARC and Oxford University 2003.

van der Weide, Roy, "GO-GARCH: A multivariate generalized orthogonal GARCH model," Journal of Applied Econometrics, 2002, 17, 549-564.

Vasicek, Oldrich, "An Equilibrium Characterization of the Term Structure," Journal of Financial Economics, 1977, 5, 177-188. 


\section{A The models of interest rates}

\section{A.1 The Heath, Jarrow, Morton (1992) model}

The HJM model is based on the assumptions (HJM.1) and (HJM.2). The definition of forward rates $f(t, T)$ allows us to write the equation for the instant interest rate $r_{t}=f(t, t)$. Then, the savings account satisfies following equation:

$$
B_{t}=\exp \left(\int_{0}^{t} f(u, u) d u\right) \quad \forall t \in\left\langle 0, T^{*}\right\rangle .
$$

The following lema describes the dynamics of prices of bonds $P(t, T)$ under the actual (real) probability measure $\mathbb{P}$.

Lemma 1 The prices of bonds $P(t, T)$ satisfy relationship

$$
d P(t, T)=P(t, T)\left(a(t, T) d t+b(t, T) \cdot d W_{t}\right),
$$

where $a$ and $b$ are defined as

$$
a(t, T)=f(t, t)-\alpha^{*}(t, T)+\frac{1}{2}\left|\sigma^{*}(t, T)\right|^{2}, \quad b(t, T)=-\sigma^{*}(t, T),
$$

and for arbitrary $t \in\langle 0, T\rangle$ is

$$
\alpha^{*}(t, T)=\int_{t}^{T} \alpha(t, u) d u, \quad \sigma^{*}(t, T)=\int_{t}^{T} \sigma(t, u) d u .
$$

Proof: Let's denote $I_{t}=\ln P(t, T)$. From (1) and (2) we get

$$
I_{t}=-\int_{t}^{T} f(0, u) d u-\int_{t}^{T} \int_{0}^{t} \alpha(v, u) d v d u-\int_{t}^{T} \int_{0}^{t} \sigma(v, u) \cdot d W_{v} d u .
$$

From the Fubini theorem and technical conditions of HJM model follows that

$$
I_{t}=-\int_{t}^{T} f(0, u) d u-\int_{0}^{t} \int_{t}^{T} \alpha(v, u) d v d u-\int_{0}^{t} \int_{t}^{T} \sigma(v, u) \cdot d W_{v} d u
$$

or equivalently

$$
\begin{aligned}
I_{t}= & -\int_{0}^{T} f(0, u) d u-\int_{0}^{t} \int_{v}^{T} \alpha(v, u) d v d u-\int_{0}^{t} \int_{v}^{T} \sigma(v, u) \cdot d W_{v} d u+ \\
& +\int_{0}^{t} f(0, u) d u+\int_{0}^{t} \int_{v}^{t} \alpha(v, u) d v d u+\int_{0}^{t} \int_{v}^{t} \sigma(v, u) \cdot d W_{v} d u .
\end{aligned}
$$


The instantaneous interest rate can be written as

$$
r_{u}=f(u, u)=f(0, u)+\int_{0}^{u} \alpha(v, u) d v+\int_{0}^{u} \sigma(v, u) \cdot d W_{v} .
$$

From this follows

$$
I_{t}=I_{0}+\int_{0}^{t} r_{u} d u-\int_{0}^{t} \int_{u}^{T} \alpha(u, v) d v d u-\int_{0}^{t} \int_{u}^{T} \sigma(u, v) d v \cdot d W_{u} .
$$

Taking into account (14) one gets:

$$
I_{t}=I_{0}+\int_{0}^{t} r_{u} d u-\int_{0}^{t} \alpha^{*}(u, T) d u-\int_{0}^{t} \sigma^{*}(u, T) \cdot d W_{u} .
$$

It is enough now to use the Ito theorem to yield the claim of the lemma.

Let us now consider $T$ as a particular fixed maturity. If one defines the discounted bond process as $Z(t, T)=B_{t}^{-1} P(t, T)$, then it satisfies the following equation:

$$
d Z(t, T)=Z(t, T)\left(b(t, T) \cdot d W_{t}+\left(a(t, T)-r_{t}\right) d t\right)
$$

Also let us define process $\gamma_{t}$ as such a change of drift of process $Z(t, T)$ that it becomes a martingale. Then with the help of the Girsanov theorem, there exists a measure $\mathbb{P}^{*}$ equivalent with the real measure $\mathbb{P}$ such that $W_{t}^{*}=W_{t}+\int_{0}^{t} \gamma_{s} d s$ is $\mathbb{P}^{*}$-Brownian motion. These measure will be denoted as risk-neutral. Then the process for the discounted bond can be written as

$$
d Z(t, T)=Z(t, T) b(t, T) d W_{t}^{*} .
$$

The dynamics of the bond prices is under the risk-neutral measure

$$
d P(t, T)=P(t, T)\left(b(t, T) d W_{t}^{*}+r_{t} d t\right) .
$$

Let us assume, that there is a claim $X$, which pays in time $S<T$. Let us define the process $E_{t}$ as $\mathbb{P}^{*}$ martingale:

$$
E_{t}=\mathbb{E}_{\mathbb{P}^{*}}\left(B_{S}^{-1} X \mid \mathcal{F}_{t}\right)
$$

Now, one can use the martingale representation theorem. This theorem states that there exists $\mathcal{F}$-predictable process $\phi$ such that

$$
E_{t}=E_{0}+\int_{0}^{t} \phi_{s} d Z(s, T)
$$


If one defines a replication portfolio formed with the $T$-bond and saving account $B_{t}$ such that the portfolio is replicating claim $X$ in the time $S$. More concretely, in time $t$ one holds

- $\phi_{t}$ units of the $T$-bond and

- $\psi_{t}=E_{t}-\phi_{t} Z(t, T)$ units of saving account.

This portfolio has this value in time $t$ :

$$
\begin{aligned}
V_{t} & =\phi_{t} P(t, T)+\psi_{t} B_{t}=\phi_{t} P(t, T)+\left(E_{t}-\phi_{t} Z(t, T)\right) B_{t}=B_{t} E_{t} \\
V_{t} & =B_{t} \mathbb{E}_{\mathbb{P}^{*}}\left(B_{S}^{-1} X \mid \mathcal{F}_{t}\right) .
\end{aligned}
$$

So, if $X$ is the payment of a derivative maturing in time $S$ then its value in time $t$ is

$$
V_{t}=\mathbb{E}_{\mathbb{P} *}\left(\exp \left(-\int_{t}^{T} r_{s} d s\right) X \mid \mathcal{F}_{t}\right)
$$

However, the bond maturing in time $S$ is the claim $X=1$. Using (18), it follows that its non-arbitrage value has to be $B_{t} \mathbb{E}_{\mathbb{P}^{*}}\left(B_{S}^{-1} \mid \mathcal{F}_{t}\right)$, respectively

$$
P(t, S)=\mathbb{E}_{\mathbb{P}^{*}}\left(\exp \left(-\int_{t}^{S} r_{s} d s\right) \mid \mathcal{F}_{t}\right) \quad t \leq S \leq T .
$$

The discounted $S$-bond can be written than as

$$
Z(t, S)=B_{t}^{-1} P(t, S)=\mathbb{E}_{\mathbb{P} *}\left(B_{S}^{-1} \mid \mathcal{F}_{t}\right)
$$

It means that even process $Z(t, S)$ is a martingale under $\mathbb{P}^{*}$ measure. From this fact follows that the process $\gamma_{t}$ has to be equal for all maturities and thus it is independent from $T$. If one rewrites the definition of the process $\gamma_{t}$ and he uses that $\frac{\partial \gamma_{t}}{\partial T}=0$ he gets

$$
\begin{aligned}
\int_{t}^{T} \alpha(t, u) d u & =\frac{1}{2} b^{2}(t, T)-b(t, T) \gamma_{t} \\
\alpha(t, T) & =\sigma(t, T)\left(\gamma_{t}-b(t, T)\right)
\end{aligned}
$$

This proves the theorem 1 . This theorem actually states that under the riskneutral measure the forward rates cannot have arbitrary drifts but only drifts derived from the volatility process. 


\section{A.2 The Brace, Gatarek, Musiela (1997) model}

In this section the dynamics of $L(t, T)$ rates, defined in 6 , is derived under the risk-neutral measure. This derivation is based on the original Brace et al. (1997) article. The advantage of the BGM is that the $L(t, T)$ rates can be modelled as lognormal.

From (6) a (1) one gets

$$
L(t, T)=\frac{\exp \left(\int_{T}^{T+\delta} f(t, u) d u\right)-1}{\delta} .
$$

In (5) one want to choose the volatility $\sigma(t, T)$ such that it would be possible to obtain the equation for $L(t, T)$ in the following form:

$$
d L(t, T)=(\cdots) d t+L(t, T) \gamma(t, T) \cdot d W_{t}^{*}
$$

for some $\gamma(t, T)$. From (5) follows:

$$
\begin{aligned}
d \int_{T}^{T+\delta} f(t, u) d u & =\int_{T}^{T+\delta} d f(t, u) d u= \\
& =\int_{T}^{T+\delta} \sigma(t, u) b(t, u) d u+\int_{T}^{T+\delta} \sigma(t, u) d W_{t}^{*}= \\
& =\int_{T}^{T+\delta} \frac{1}{2} \frac{\partial b^{2}(t, u)}{\partial u} d u+[b(t, T)-b(t, T+\delta)] d W_{t}^{*}= \\
& =\frac{1}{2}\left[b^{2}(t, T)-b^{2}(t, T+\delta)\right] d t+[b(t, T+\delta)-b(t, T)] d W_{t}^{*}
\end{aligned}
$$

Then

$$
\begin{aligned}
d L(t, T)= & d \frac{\exp \left(\int_{T}^{T+\delta} f(t, u) d u\right)-1}{\delta} \\
= & \frac{1}{\delta} \exp \left(\int_{T}^{T+\delta} f(t, u) d u\right) d \int_{T}^{T+\delta} f(t, u) d u+ \\
& \quad+\frac{1}{2 \delta} \exp \left(\int_{T}^{T+\delta} f(t, u) d u\right)\left(d \int_{T}^{T+\delta} f(t, u) d u\right)^{2}= \\
\stackrel{(21)}{=} \frac{1}{\delta}[1+\delta L(t, T)]\left[\frac{1}{2}\left[b^{2}(t, T+\delta)-b^{2}(t, T)\right] d t+\right. & \left.+[b(t, T)-b(t, T+\delta)] d W_{t}^{*}+\frac{1}{2}[b(t, T)-b(t, T+\delta)]^{2} d t\right] \\
= & \frac{1}{\delta}[1+\delta L(t, T)][b(t, T)-b(t, T+\delta)]\left[-b(t, T+\delta) d t+d W_{t}^{*}\right]
\end{aligned}
$$


If one defines now the process $\lambda(t, T)$ as:

$$
\lambda(t, T) L(t, T)=\frac{1}{\delta}[1+\delta L(t, T)][b(t, T)-b(t, T+\delta)],
$$

he obtain

$$
d L(t, T)=-\lambda(t, T) L(t, T) b(t, T+\delta) d t+\lambda(t, T) L(t, T) d W_{t}^{*} .
$$

Equation (24) can be conveniently rewritten as

$$
d L(t, T)=\lambda(t, T) L(t, T)\left[-b(t, T+\delta) d t+d W_{t}^{*}\right] .
$$

If one combines the previous condition (24) with the Girsanov theorem, he obtains

$$
d L(t, T)=\lambda(t, T) L(t, T) d W_{t}^{T+\delta},
$$

where for all $t \in\langle 0, T+\delta\rangle$

$$
W_{t}^{T+\delta}=W_{t}^{*}-\int_{0}^{T+\delta} b(u, T+\delta) d u .
$$

The process $W_{t}^{T+\delta}$ is Brownian motion under the measure $\mathbb{P}_{T+\delta} \sim \mathbb{P}^{*}$, defined with the help of the Radon-Nikodym derivative as

$$
\frac{d \mathbb{P}_{T+\delta}}{d \mathbb{P}^{*}}=\exp \left(\int_{0}^{T+\delta} b(u, T+\delta) \cdot d W_{u}^{*}-\frac{1}{2} \int_{0}^{T+\delta}|b(u, T+\delta)|^{2} d u\right) .
$$

Let us denote the measure $\mathbb{P}_{\mathbb{T}+\delta}$ as the forward rate connected with the maturity $T+\delta$. Musiela and Rutkowski (1998) show that if the price of some tradable asset (with no dividends and coupons), expressed in $P(t, T)$ units, is martingale under the $\mathbb{P}_{\mathbb{T}}$ measure, so as numeraire under this measure is the price of a bond maturing in the time $T$.

In the following part the model of forward LIBOR rates for the case of discrete time tenor will be constructed, based on the following assumptions:

(LR.1): For the arbitrary maturity $T \leq T^{*}-\delta$, is given bounded, deterministic function $\lambda(\cdot, T) \in \mathbb{R}^{d}$, which represents the volatility of the forward rate $L(\cdot, T)$ process.

(LR.2) Let us assume the existence of a strictly decreasing and positive initial term structure $P(0, T), T \in\left\langle 0, T^{*}\right\rangle$, which means also the existence of the initial 
curve $L(0, T)$ of forward rates.

$$
L(0, T)=\delta^{-1}\left(\frac{P(0, T)}{P(0, T+\delta)}-1\right) \quad \forall T \in\left\langle 0, T^{*}-\delta\right\rangle .
$$

\section{Discrete tenor}

Let us assume that the time horizon $T^{*}$ is a multiple of $\delta$; let us say $T^{*}=M \delta$ for some natural $M$. In this subpart we will concentrate on the forward LIBOR rates with maturities in discrete time tenor $\left\{0, T_{(M-1) \delta}, T_{(M-2) \delta}, \cdots\right.$,

$\left.T_{\delta}, T^{*}\right\}$, where $T_{m \delta}=T^{*}-m \delta$ for $m=1,2, \cdots, M-1$. This procedure is based on backward induction, when one begins with the definition of the LIBOR rate with the longest maturity possible, $L\left(t, T_{\delta}\right)$. Let us assume that we have specified lognormal volatilities $\lambda\left(t, T_{m \delta}\right)$ for $m=1,2, \cdots, M-1$. Let us postulate that the rate $L\left(t, T_{\delta}\right)$ is under the probability measure $\mathbb{P}_{T^{*}}$ driven by the following stochastic differential equation:

$$
d L\left(t, T_{\delta}\right)=L\left(t, T_{\delta}\right) \lambda\left(t, T_{\delta}\right) \cdot d W_{t}^{T^{*}}
$$

with initial condition

$$
d L\left(0, T_{\delta}\right)=\delta^{-1}\left(\frac{P\left(0, T_{\delta}\right)}{P\left(0, T^{*}\right)}-1\right)
$$

Because the initial term structure is strictly decreasing, it is clear that $L\left(t, T_{\delta}\right)$ is positive and for fixed $t \leq T^{*}-\delta$ the random variable $L\left(t, T_{\delta}\right)$ has the lognormal distribution under $\mathbb{P}_{T^{*}}$. This way the dynamics of LIBOR rates with maturity in the last date of our tenor is defined.

In the next step the forward LIBOR rate for the date $T_{2 \delta}^{*}$ with the use of (23) will be defined, where $T=T_{\delta}$, so that mean and volatility are specified as

$$
\begin{aligned}
\lambda\left(t, T_{\delta}\right) & =\frac{1+\delta L\left(t, T_{\delta}\right)}{\delta L\left(t, T_{\delta}\right)}\left[b\left(t, T_{\delta}\right)-b\left(t, T^{*}\right)\right] \\
\mu\left(t, T_{\delta}, T^{*}\right) & =\frac{\delta L\left(t, T_{\delta}\right)}{1+\delta L\left(t, T_{\delta}\right)} \lambda\left(t, T_{\delta}\right)
\end{aligned}
$$

where as $\mu(t, T, T+\delta)$ is denoted $b(t, T)-b(t, T+\delta)$. Let us define process $W_{t}^{T_{\delta}}$, corresponding with the date $T_{\delta}$ as

$$
W_{t}^{T_{\delta}}=W_{t}^{T^{*}}-\int_{0}^{t} \mu\left(u, T_{\delta}, T^{*}\right) d u \quad \forall t \in\left\langle 0, T_{\delta}\right\rangle
$$

This process is connected with the date $T_{\delta}$ (due to (27), it describes the rela- 
tionship between Brownian motions under measures $\mathbb{P}_{T+\delta}$ a $\left.\mathbb{P}^{*}\right)$

Because $\mu\left(t, T_{\delta}, T^{*}\right)$ is bounded from the Girsanov theorem the existence of this process is clear and probability measure associated to it $\mathbb{P}_{T_{\delta}} \sim \mathbb{P}_{T^{*}}$ under which process $W_{T_{\delta}}$ is an Brownian motion. It is given by Radon-Nikodym derivative

$$
\frac{d \mathbb{P}_{T \delta}}{d \mathbb{P}_{T^{*}}}=\exp \left(\int_{0}^{T_{\delta}} \mu(u, T+\delta) \cdot d W_{u}^{T^{*}}-\frac{1}{2} \int_{0}^{T_{\delta}}|\mu(u, T+\delta)|^{2} d u\right) .
$$

From (28) one can see that it is the forward rate connected with maturity $T_{\delta}$. Now it is possible to specify the dynamics of LIBOR rate for the maturity $T_{2 \delta}$ under the measure $\mathbb{P}_{T \delta}$. Analogically as in (29) let's define

$$
d L\left(t, T_{2 \delta}\right)=L\left(t, T_{2 \delta}\right) \lambda\left(t, T_{2 \delta}\right) \cdot d W_{t}^{T_{\delta}}
$$

with the initial condition

$$
L\left(0, T_{2 \delta}\right)=\delta^{-1}\left(\frac{P\left(0, T_{2 \delta}\right)}{P\left(0, T_{\delta}\right)}-1\right) .
$$

From (23) we get the value of the needed change of Brownian motion $W_{t}^{T_{\delta}}$ in order to get to the values connected with the date $T_{2 \delta}$ :

$$
\mu\left(t, T_{2 \delta}, T_{\delta}\right)=\frac{\delta L\left(t, T_{2 \delta}\right)}{1+\delta L\left(t, T_{2 \delta}\right)} \lambda\left(t, T_{2} \delta\right)=b\left(t, T_{2 \delta}\right)-b\left(t, T_{\delta}\right) .
$$

If we have defined the process $\mu\left(t, T_{2 \delta}, T_{\delta}\right)$, we can define the pair $\left(W^{T_{2 \delta}}, \mathbb{P}_{T_{2 \delta}}\right)$, connected with the maturity $T_{2 \delta}$, and so on. With backward induction to the first relevant date $T_{(M-1) \delta}$, we can construct the class of forward LIBOR rates $L\left(t, T_{m \delta}\right), m=1, \cdots, M-1$. With this procedure lognormal distribution of each process $L\left(t, T_{m \delta}\right)$ is assured under corresponding forward probability measure $\mathbb{P}_{T_{(m-1) \delta}}$. We have for all $m=1, \cdots, M-1$

$$
d L\left(t, T_{m \delta}\right)=L\left(t, T_{m \delta}\right) \lambda\left(t, T_{m \delta}\right) \cdot d W_{t}^{T_{(m-1) \delta}},
$$

where $d W_{t}^{T_{(m-1) \delta}}$ is a Brownian motion under $\mathbb{P}_{T_{(m-1) \delta}}$.

This finishes the derivation of the lognormal model of forward LIBOR rates under discrete tenor. Before the end, let us bring in the explicit relationship among the Brownian motions connected with the adjacent maturities:

$$
W_{t}^{T_{m-1 \delta}}=W_{t}^{T_{m \delta}}+\int_{0}^{t} \frac{\delta L\left(u, T_{m \delta}\right)}{1+\delta L\left(u, T_{m \delta}\right)} \lambda\left(u, T_{m \delta}\right) d u .
$$




\section{B Figures and Tables}

\section{B.1 Figures}

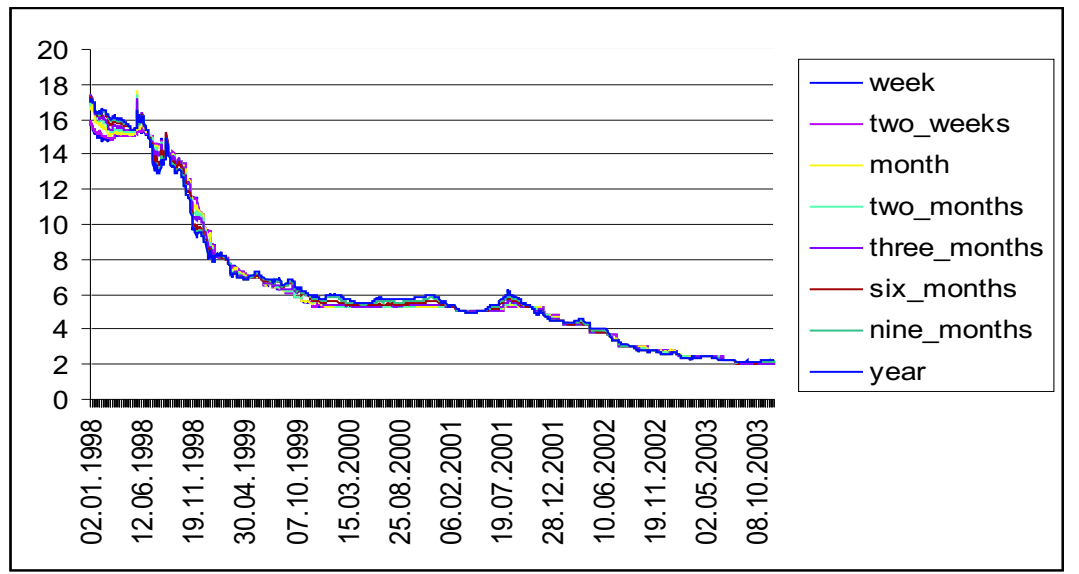

Figure 1: Time evolution of PRIBOR rates 


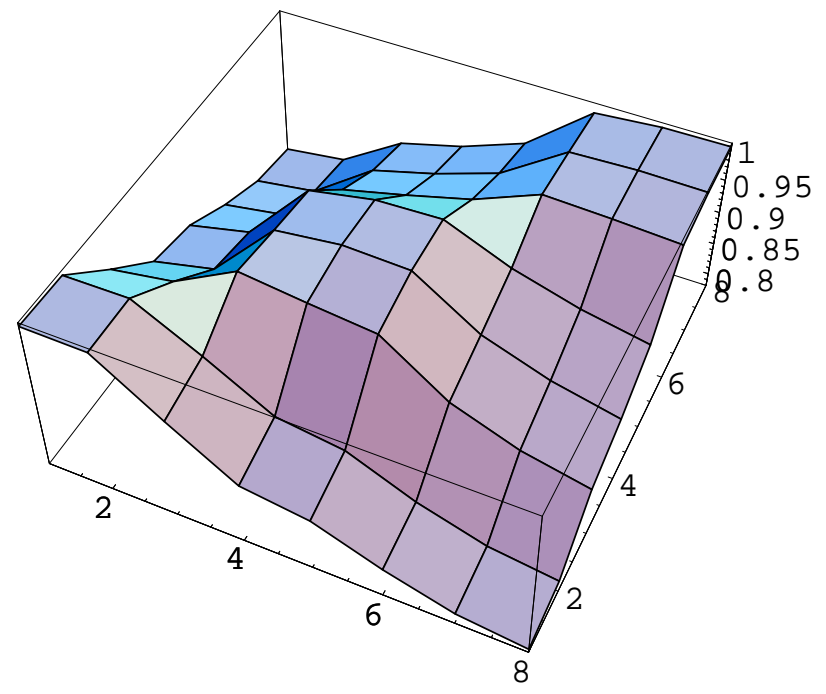

Figure 2: Estimated correlation surface of CZK as of 28 November 2003

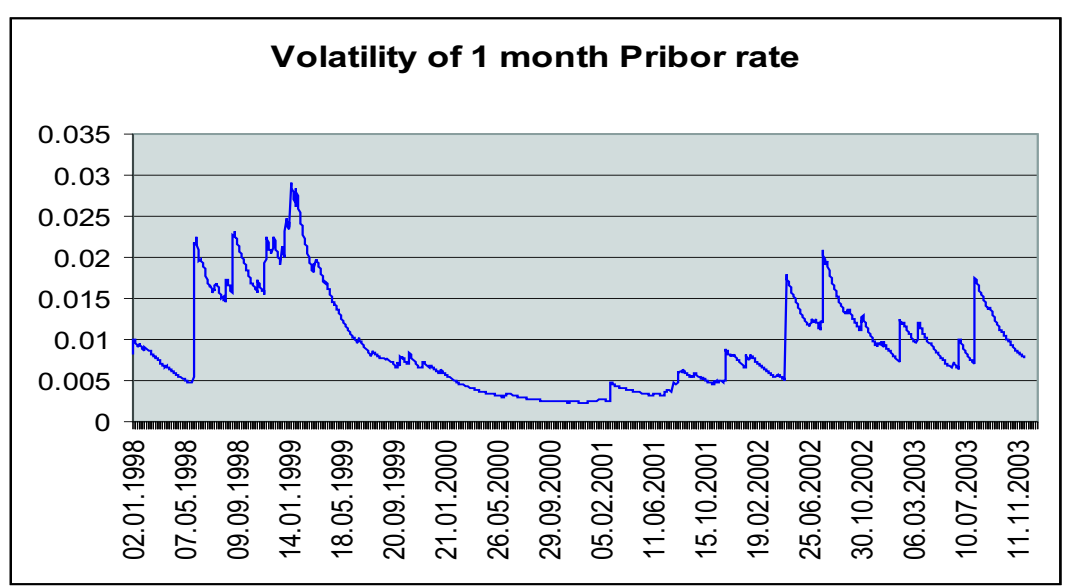

Figure 3: Estimated conditional volatility of 1 month PRIBOR rate 


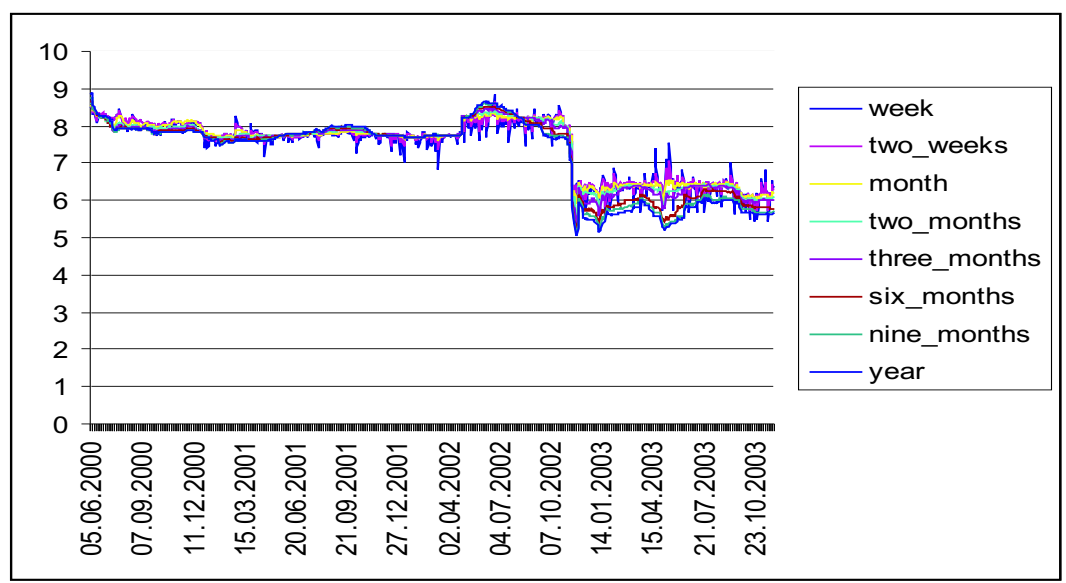

Figure 4: Time evolution of BRIBOR rates

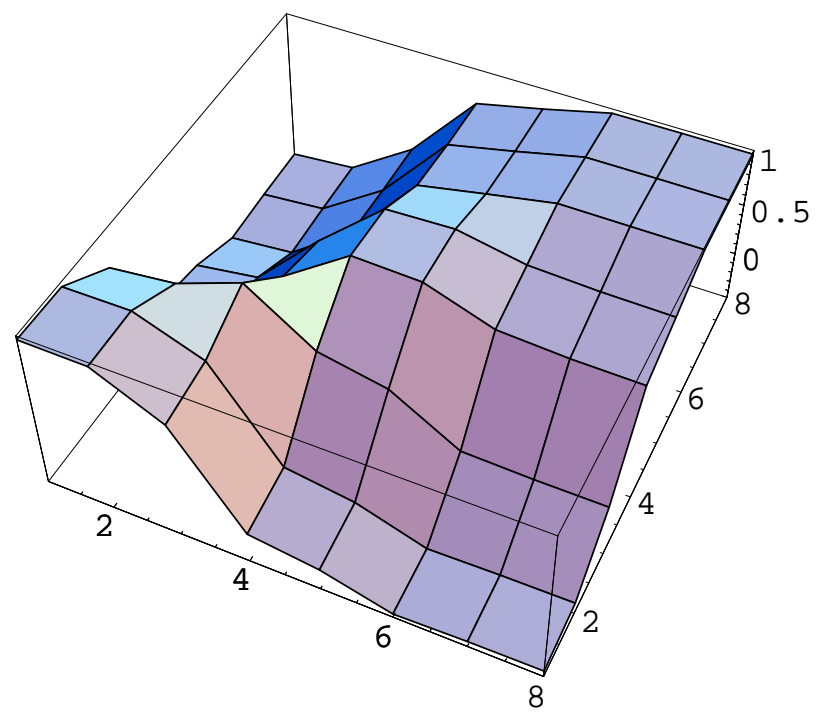

Figure 5: Estimated correlation surface of SKK as of 28 November 2003 


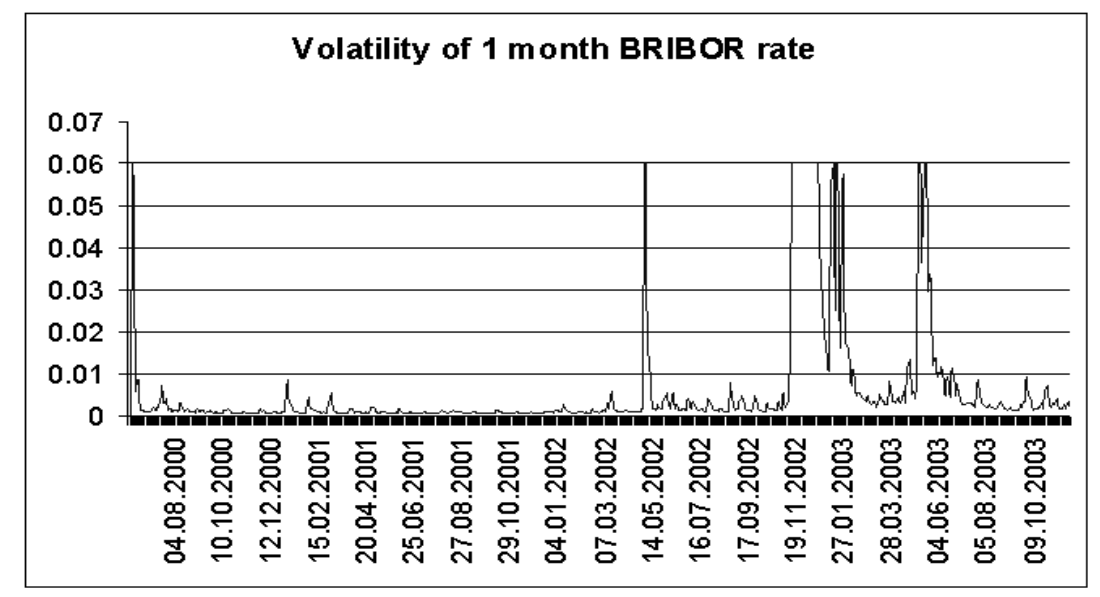

Figure 6: Estimated conditional volatility of 1 month BRIBOR rate

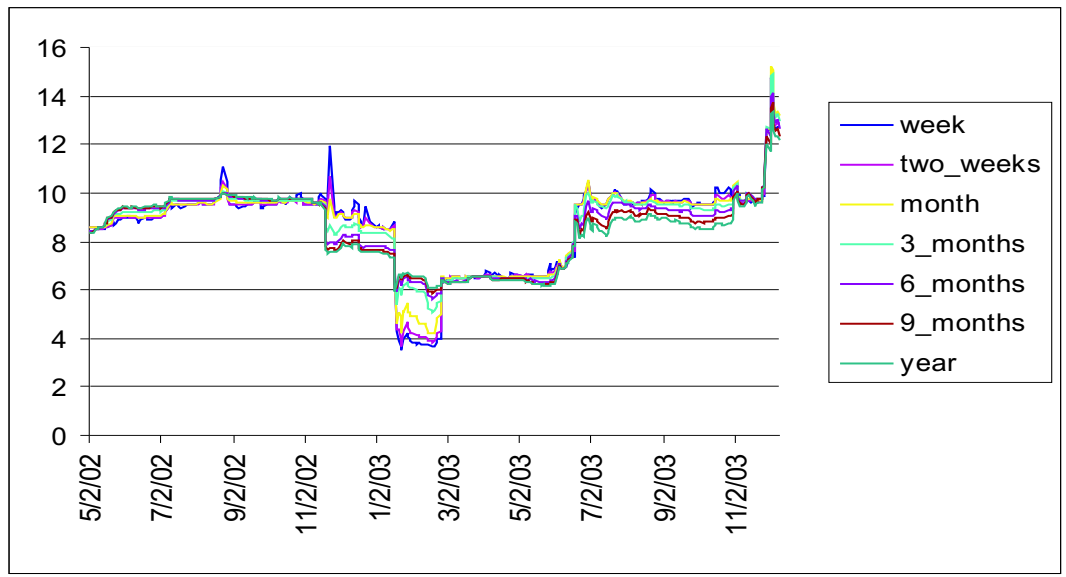

Figure 7: Time evolution of BUBOR rates 


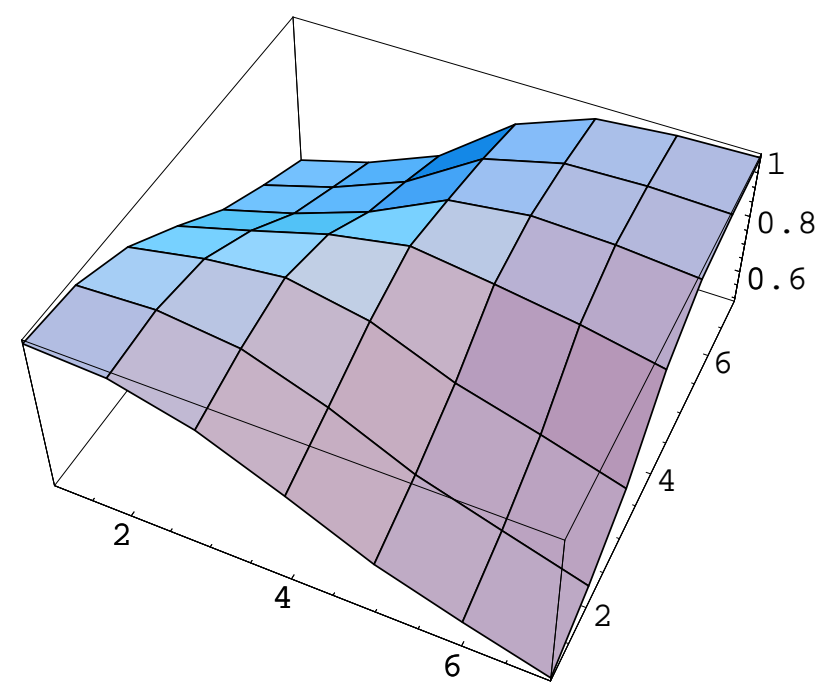

Figure 8: Estimated correlation surface of HUF as of 28 November 2003

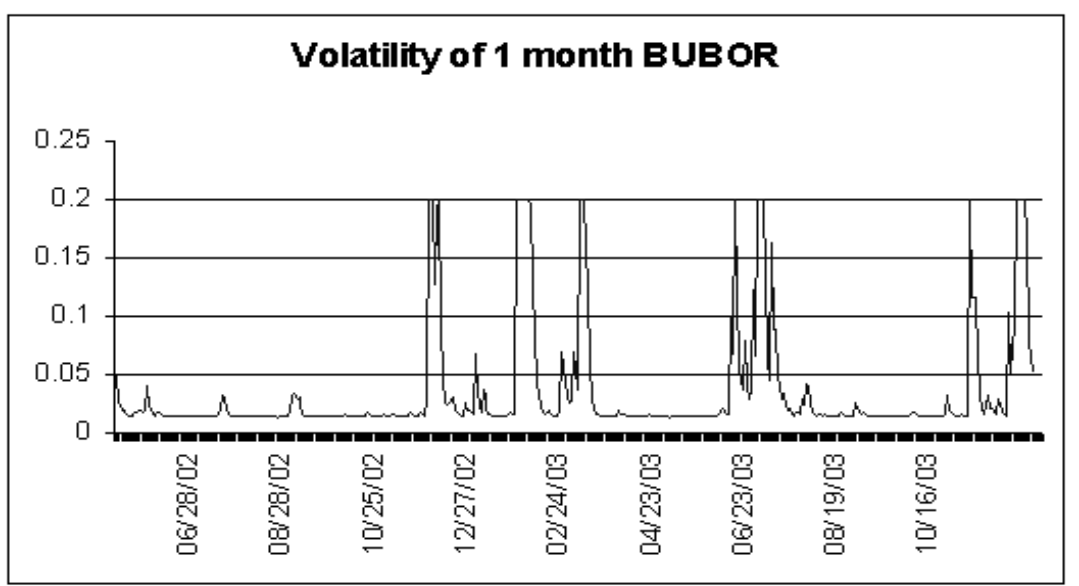

Figure 9: Estimated conditional volatility of 1 month BUBOR rate 


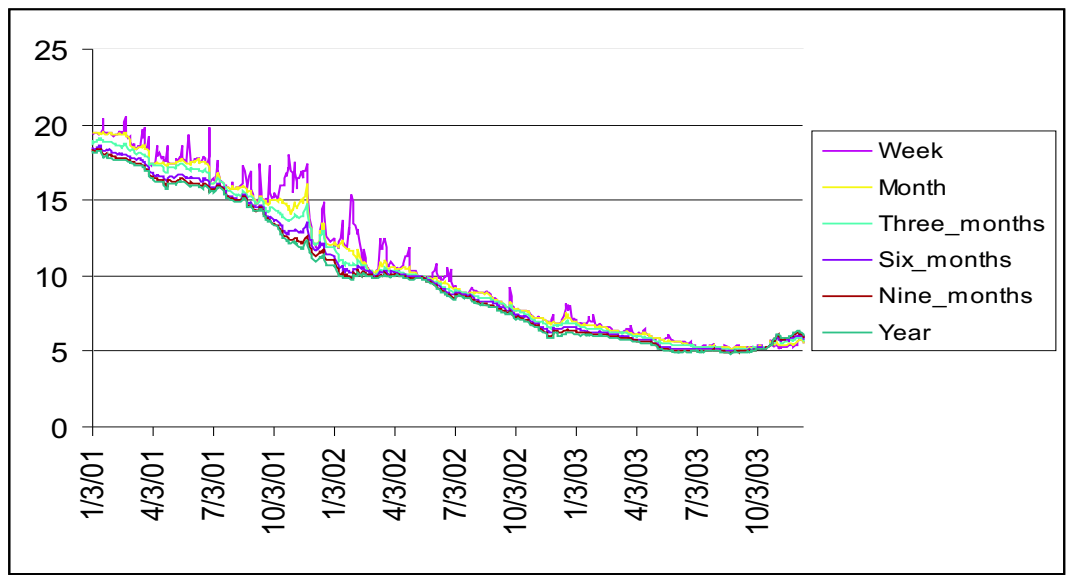

Figure 10: Time evolution of WIBOR rates

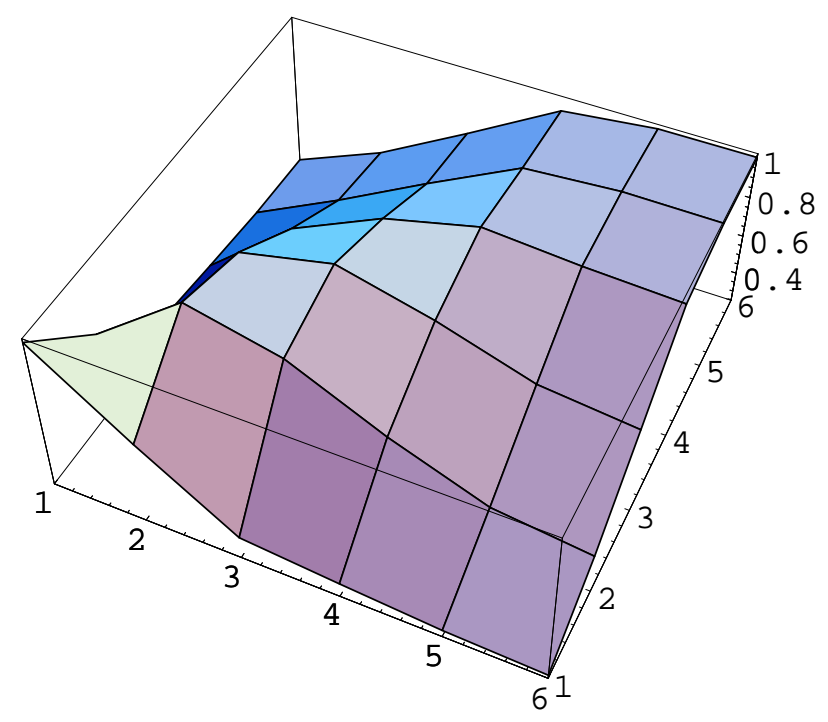

Figure 11: Estimated correlation surface of PLZ as of 28 November 2003 


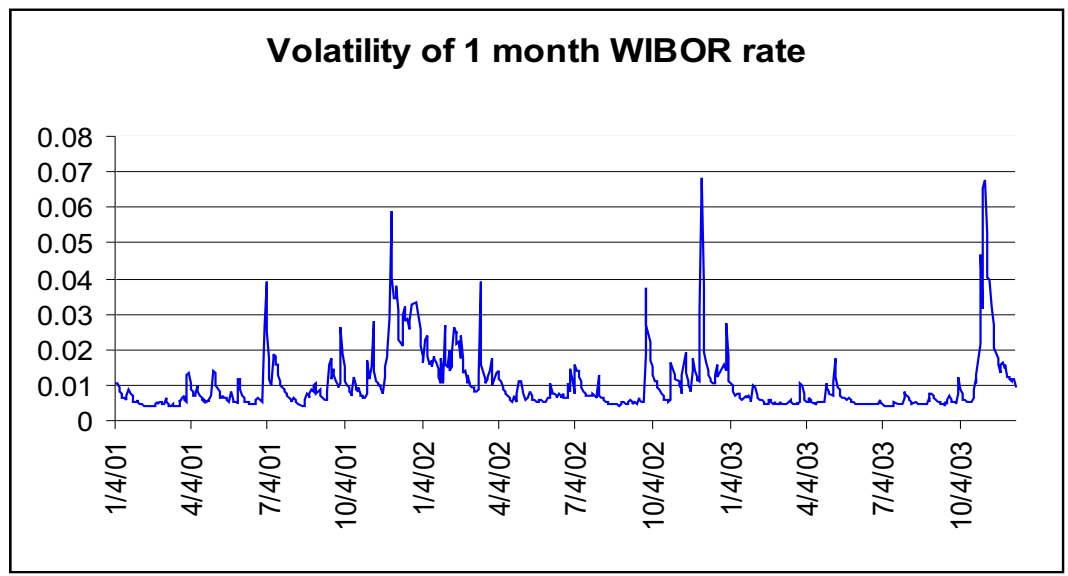

Figure 12: Estimated conditional volatility of 1 month WIBOR rate 


\begin{tabular}{|c|c|c|c|c|c|c|}
\hline Series & Mean & Std. Dev. & Minimum & Maximum & Sum & $Q_{10}$ stat \\
\hline Y_WEEK & -0.00132 & 0.00883 & -0.112 & 0.0798 & -1.978 & 9.59 \\
Y_2W & -0.00132 & 0.00877 & -0.109 & 0.0915 & -1.982 & 8.99 \\
Y_M & -0.00135 & 0.00916 & -0.107 & 0.1101 & -2.018 & 22.1 \\
Y_2M & -0.00136 & 0.00860 & -0.107 & 0.1031 & -2.036 & 11.4 \\
Y_3M & -0.00137 & 0.00838 & -0.103 & 0.0832 & -2.044 & 15.9 \\
Y_6M & -0.00135 & 0.00848 & -0.084 & 0.0853 & -2.024 & 28.8 \\
Y_9M & -0.00133 & 0.00822 & -0.079 & 0.0724 & -1.990 & 72.3 \\
Y_Y & -0.00131 & 0.00842 & -0.079 & 0.0726 & -1.956 & 83.4 \\
\hline
\end{tabular}

Table 1: Characteristics of time series for CZK

\begin{tabular}{|c|c|c|c|c|c|c|c|c|}
\hline Component & 1 & 2 & 3 & 4 & 5 & 6 & 7 & 8 \\
\hline Y_WEEK & 0.322 & -0.495 & 0.411 & -0.249 & 0.012 & 0.133 & 0.631 & 0.050 \\
Y_2W & 0.332 & -0.477 & 0.316 & -0.024 & 0.037 & -0.056 & -0.742 & -0.074 \\
Y_M & 0.365 & -0.245 & -0.303 & 0.730 & -0.169 & -0.342 & 0.183 & 0.010 \\
Y_2M & 0.376 & -0.058 & -0.521 & -0.021 & 0.206 & 0.729 & -0.064 & 0.015 \\
Y_3M & 0.376 & 0.057 & -0.423 & -0.577 & 0.162 & -0.558 & 0.019 & -0.007 \\
Y_6M & 0.361 & 0.327 & 0.097 & -0.143 & -0.791 & 0.115 & -0.080 & 0.292 \\
Y_9M & 0.350 & 0.408 & 0.238 & 0.082 & 0.045 & 0.036 & 0.073 & -0.798 \\
Y_Y & 0.339 & 0.432 & 0.334 & 0.206 & 0.522 & -0.052 & -0.011 & 0.517 \\
\hline Eigenvalue & 6.314 & 1.142 & 0.262 & 0.099 & 0.068 & 0.051 & 0.030 & 0.030 \\
Total variance expl. & 0.789 & 0.932 & 0.964 & 0.977 & 0.985 & 0.992 & 0.996 & 1.000 \\
\hline
\end{tabular}

Table 2: Principal components weights for CZK 


\begin{tabular}{|c|c|c|c|c|c|c|}
\hline \multirow{2}{*}{ Component } & \multicolumn{2}{|c|}{ First } & \multicolumn{2}{c|}{ Second } & \multicolumn{2}{c|}{ Third } \\
\cline { 2 - 7 } & Coefficient & $t$-stat & Coefficient & $t$-stat & Coefficient & $t$-stat \\
\hline Constant & -0.033 & -0.269 & 0.024 & 1.297 & 0.004 & 0.319 \\
$b_{1}$ & 0.414 & 2.548 & 0.214 & 2.780 & 0.081 & 2.025 \\
$b_{2}$ & - & - & 0.077 & 2.084 & - & - \\
$\alpha_{0}$ & 3.952 & 2.921 & 0.006 & 0.502 & 0.007 & 1.335 \\
$\alpha_{1}$ & 0.905 & 2.486 & 0.069 & 0.831 & 0.187 & 2.651 \\
$\beta_{1}$ & 0.011 & 0.217 & 0.268 & 2.298 & 0.059 & 1.547 \\
$\beta_{2}$ & - & - & 0.658 & 6.792 & 0.743 & 13.534 \\
\hline \hline Log Likelihood & -3368.12 & -1975.57 & \multicolumn{2}{c}{-877.21} \\
Schwarz B.I.C. & 3386.58 & 2001.14 & 899.12 \\
$Q_{10}$ stat & \multicolumn{2}{|c|}{10.8} & 17.9 & \multicolumn{2}{c}{9.68} \\
$Q_{10}^{2}$ stat & \multicolumn{2}{|c|}{0.472} & \multicolumn{2}{c}{10.8} & \multicolumn{2}{c}{2.71} \\
LM test stat & \multicolumn{2}{|c|}{0.309} & \multicolumn{3}{c}{9.37} & 2.78 \\
\hline
\end{tabular}

Table 3: Regression results for CZK

\begin{tabular}{|c|c|c|c|c|c|c|}
\hline Series & Mean & Std. Dev. & Minimum & Maximum & Sum & $Q_{10}$ stat \\
\hline Y_WEEK & 0.000221 & 0.0298 & -0.161 & 0.1661 & 0.193 & 72.9 \\
Y_2W & -0.000064 & 0.0179 & -0.179 & 0.1101 & -0.056 & 53.8 \\
Y_M & -0.000300 & 0.0095 & -0.187 & 0.0616 & -0.261 & 34.6 \\
Y_2M & -0.000352 & 0.0092 & -0.193 & 0.0615 & -0.307 & 63.3 \\
Y_3M & -0.000365 & 0.0093 & -0.179 & 0.0694 & -0.317 & 65.5 \\
Y_6M & -0.000443 & 0.0084 & -0.141 & 0.0675 & -0.386 & 189 \\
Y_9M & -0.000490 & 0.0088 & -0.158 & 0.0978 & -0.427 & 180 \\
Y_Y & -0.000503 & 0.0090 & -0.159 & 0.0992 & -0.438 & 165 \\
\hline
\end{tabular}

Table 4: Characteristics of time series for SKK

\begin{tabular}{|c|c|c|c|c|c|c|c|c|}
\hline Component & 1 & 2 & 3 & 4 & 5 & 6 & 7 & 8 \\
\hline Y_WEEK & 0.196 & -0.646 & 0.294 & -0.155 & 0.151 & -0.256 & 0.582 & 0.083 \\
Y_2W & 0.256 & -0.586 & 0.123 & -0.039 & 0.059 & 0.212 & -0.720 & -0.085 \\
Y_M & 0.373 & -0.224 & -0.502 & 0.442 & -0.550 & 0.137 & 0.203 & -0.020 \\
Y_2M & 0.395 & 0.102 & -0.479 & -0.057 & 0.388 & -0.644 & -0.184 & 0.044 \\
Y_3M & 0.399 & 0.138 & -0.256 & -0.446 & 0.328 & 0.633 & 0.221 & 0.012 \\
Y_6M & 0.381 & 0.231 & 0.269 & -0.543 & -0.610 & -0.216 & -0.099 & 0.072 \\
Y_9M & 0.386 & 0.231 & 0.363 & 0.297 & 0.129 & -0.020 & 0.087 & -0.743 \\
Y_Y & 0.383 & 0.228 & 0.384 & 0.439 & 0.154 & 0.096 & -0.044 & 0.652 \\
\hline Eigenvalue & 5.604 & 1.763 & 0.314 & 0.123 & 0.081 & 0.048 & 0.039 & 0.027 \\
Total variance expl. & 0.701 & 0.921 & 0.960 & 0.976 & 0.986 & 0.992 & 0.997 & 1.000 \\
\hline
\end{tabular}

Table 5: Principal components weights for SKK 


\begin{tabular}{|c|c|c|c|c|c|c|}
\hline \multirow[t]{2}{*}{ Component } & \multicolumn{2}{|c|}{ First } & \multicolumn{2}{|c|}{ Second } & \multicolumn{2}{|c|}{ Third } \\
\hline & Coefficient & $t$-stat & Coefficient & $t$-stat & Coefficient & $t$-stat \\
\hline Constant & -0.017 & -0.215 & 0.074 & 1.297 & 0.011 & 0.900 \\
\hline$b_{1}$ & -0.245 & -1.277 & -0.115 & 2.780 & -0.079 & -1.714 \\
\hline$b_{2}$ & 0.077 & 0.413 & -0.248 & 2.084 & -0.115 & -2.501 \\
\hline$b_{3}$ & - & - & -0.157 & 2.084 & -0.011 & -0.239 \\
\hline$\alpha_{0}$ & 0.259 & 1.601 & 0.004 & 0.502 & 0.003 & 1.308 \\
\hline$\alpha_{1}$ & 0.325 & 1.431 & 0.037 & 0.831 & 0.066 & 2.427 \\
\hline$\alpha_{2}$ & 0.264 & 0.822 & - & - & - & - \\
\hline$\beta_{1}$ & 0.405 & 2.382 & 0.957 & 6.792 & 0.919 & 27.134 \\
\hline Log Likelihood & \multicolumn{2}{|c|}{-1404.41} & \multicolumn{2}{|c|}{-1219.72} & \multicolumn{2}{|c|}{-426.24} \\
\hline Schwarz B.I.C. & \multicolumn{2}{|c|}{1428.10} & \multicolumn{2}{|c|}{1243.40} & \multicolumn{2}{|c|}{449.92} \\
\hline$Q_{10}$ stat & \multicolumn{2}{|c|}{28.2} & \multicolumn{2}{|c|}{14.5} & \multicolumn{2}{|c|}{6.58} \\
\hline$Q_{10}^{2}$ stat & \multicolumn{2}{|c|}{2.09} & \multicolumn{2}{|c|}{14.2} & \multicolumn{2}{|c|}{7.07} \\
\hline LM test stat & \multicolumn{2}{|c|}{0.656} & \multicolumn{2}{|c|}{6.917} & \multicolumn{2}{|c|}{6.410} \\
\hline
\end{tabular}

Table 6: Regression results for SKK

\begin{tabular}{|c|c|c|c|c|c|c|}
\hline Series & Mean & Std. Dev. & Minimum & Maximum & Sum & $Q_{10}$ stat \\
\hline Y_WEEK & 0.00201 & 0.0487 & -0.404 & 0.620 & 0.815 & 7.63 \\
Y_2W & 0.00183 & 0.0431 & -0.389 & 0.506 & 0.746 & 10.6 \\
Y_M & 0.00163 & 0.0371 & -0.321 & 0.313 & 0.663 & 16.6 \\
Y_3M & 0.00129 & 0.0274 & -0.197 & 0.204 & 0.524 & 16.6 \\
Y_6M & 0.00104 & 0.0229 & -0.184 & 0.179 & 0.425 & 17.3 \\
Y_9M & 0.000997 & 0.0216 & -0.180 & 0.150 & 0.404 & 13.9 \\
Y_Y & 0.000966 & 0.0218 & -0.190 & 0.127 & 0.392 & 7.42 \\
\hline
\end{tabular}

Table 7: Characteristics of time series for HUF

\begin{tabular}{|c|c|c|c|c|c|c|c|}
\hline Component & 1 & 2 & 3 & 4 & 5 & 6 & 7 \\
\hline Y_WEEK & 0.337 & -0.509 & 0.593 & 0.114 & 0.018 & 0.488 & -0.155 \\
Y_2W & 0.367 & -0.445 & 0.109 & -0.015 & 0.029 & -0.785 & 0.196 \\
Y_M & 0.389 & -0.282 & -0.570 & -0.595 & -0.144 & 0.245 & -0.095 \\
Y_3M & 0.414 & 0.035 & -0.435 & 0.596 & 0.518 & 0.113 & -0.030 \\
Y_6M & 0.401 & 0.277 & 0.007 & 0.243 & -0.613 & 0.144 & 0.554 \\
Y_9M & 0.380 & 0.393 & 0.114 & 0.046 & -0.281 & -0.227 & -0.745 \\
Y_Y & 0.352 & 0.481 & 0.329 & -0.464 & 0.505 & 0.029 & 0.255 \\
\hline Eigenvalue & 5.567 & 1.219 & 0.142 & 0.040 & 0.012 & 0.011 & 0.008 \\
Total variance expl. & 0.795 & 0.969 & 0.990 & 0.996 & 0.997 & 0.999 & 1.000 \\
\hline
\end{tabular}

Table 8: Principal components weights for HUF 


\begin{tabular}{|c|c|c|c|c|c|c|}
\hline \multirow{2}{*}{ Component } & \multicolumn{2}{|c|}{ First } & \multicolumn{2}{c|}{ Second } & \multicolumn{2}{c|}{ Third } \\
\cline { 2 - 7 } & Coefficient & $t$-stat & Coefficient & $t$-stat & Coefficient & $t$-stat \\
\hline Constant & -0.238 & -1.990 & 0.105 & 1.147 & 0.023 & 0.507 \\
$\alpha_{0}$ & 1.040 & 1.255 & 0.074 & 0.956 & 0.010 & 0.554 \\
$\alpha_{1}$ & 0.585 & 7.438 & 0.537 & 5.420 & 0.626 & 0.956 \\
$\beta_{1}$ & 0.386 & 4.738 & 0.451 & 4.512 & 0.351 & 0.539 \\
\hline \hline Log Likelihood & \multicolumn{2}{|c|}{-825.01} & -472.68 & -1.061 \\
Schwarz B.I.C. & 837.02 & 484.69 & 13.074 \\
$Q_{10}$ stat & 0.06 & 0.89 & 0.704 \\
$Q_{10}^{2}$ stat & 0.05 & 0.09 & 0.096 \\
LM test stat & 0.021 & 0.037 & 0.041 \\
\hline
\end{tabular}

Table 9: Regression results for HUF

\begin{tabular}{|c|c|c|c|c|c|c|}
\hline Series & Mean & Std. Dev. & Minimum & Maximum & Sum & $Q_{10}$ stat \\
\hline Y_WEEK & -0.00127 & 0.0298 & -0.166 & 0.196 & -0.938 & 27.0 \\
Y_M & -0.00163 & 0.0113 & -0.0811 & 0.0543 & -1.207 & 40.3 \\
Y_3M & -0.00160 & 0.00816 & -0.0523 & 0.0540 & -1.183 & 8.9 \\
Y_6M & -0.00154 & 0.00755 & -0.0455 & 0.0516 & -1.140 & 32.0 \\
Y_9M & -0.00151 & 0.00741 & -0.0431 & 0.0544 & -1.118 & 55.7 \\
Y_Y & -0.00148 & 0.00755 & -0.0326 & 0.0573 & -1.097 & 66.1 \\
\hline
\end{tabular}

Table 10: Characteristics of time series for PLZ

\begin{tabular}{|c|c|c|c|c|c|c|}
\hline Component & 1 & 2 & 3 & 4 & 5 & 6 \\
\hline Y_WEEK & 0.259 & 0.717 & -0.590 & 0.254 & -0.060 & 0.003 \\
Y_M & 0.387 & 0.453 & 0.418 & -0.659 & 0.182 & -0.001 \\
Y_3M & 0.445 & 0.060 & 0.539 & 0.507 & -0.499 & 0.025 \\
Y_6M & 0.451 & -0.201 & 0.029 & 0.360 & 0.782 & 0.112 \\
Y_9M & 0.442 & -0.326 & -0.264 & -0.169 & -0.142 & -0.760 \\
Y_Y & 0.429 & -0.357 & -0.337 & -0.288 & -0.285 & 0.639 \\
\hline Eigenvalue & 4.091 & 1.154 & 0.331 & 0.194 & 0.154 & 0.074 \\
Total variance expl. & 0.682 & 0.874 & 0.930 & 0.962 & 0.988 & 1.000 \\
\hline
\end{tabular}

Table 11: Principal components weights for PLZ

\begin{tabular}{|c|c|c|c|c|c|c|}
\hline \multirow{2}{*}{ Component } & \multicolumn{2}{|c|}{ First } & \multicolumn{2}{c|}{ Second } & \multicolumn{2}{c|}{ Third } \\
\cline { 2 - 7 } & Coefficient & $t$-stat & Coefficient & $t$-stat & Coefficient & $t$-stat \\
\hline Constant & 0.063 & .929 & 0.055 & 1.472 & -0.048 & -0.269 \\
$b$ & 0.168 & 3.617 & 0.072 & 1.224 & -0.125 & -2.465 \\
$\alpha_{0}$ & 0.203 & 1.636 & 0.365 & 2.598 & 0.015 & 0.767 \\
$\alpha_{1}$ & 0.115 & 2.577 & 0.399 & 2.579 & 0.071 & 1.146 \\
$\beta_{1}$ & 0.831 & 13.233 & 0.363 & 2.477 & 0.878 & 7.223 \\
\hline \hline Log Likelihood & -1458.68 & -1053.24 & -591.38 \\
Schwarz B.I.C. & 1475.19 & 1066.45 & 607.89 \\
$Q_{10}$ stat & 10.8 & 3.56 & 8.74 \\
$Q_{10}^{2}$ stat & 8.69 & 6.09 & 6.42 \\
LM test stat & 0.575 & 1.439 & 2.993 \\
\hline
\end{tabular}

Table 12: Regression results for PLZ 
CERGE-EI

P.O.BOX 882 Politických vezòù 7

11121 Prague 1

Czech Republic http://www.cerge-ei.cz 